Global Ecology and Biogeography

May 2016, Volume 25, Issue 5, Pages 503-515

http://dx.doi.org/10.1111/geb.12431

http://archimer.ifremer.fr/doc/00311/42201/

(C) 2016 John Wiley \& Sons Ltd

\title{
Linking basin-scale connectivity, oceanography and population dynamics for the conservation and management of marine ecosystems
}

\author{
Dubois Mélodie ${ }^{1}$, Rossi Vincent ${ }^{1,{ }^{*}}$, Ser-Giacomi Enrico ${ }^{1}$, Arnaud-Haond Sophie ${ }^{2}$, López Cristóbal ${ }^{1}$, \\ Hernández-García Emilio ${ }^{1}$
}

${ }^{1}$ IFISC (Institute for Cross-Disciplinary Physics and Complex Systems); CSIC-UIB; Palma de Mallorca 07122 Spain

2 Ifremer, UMR MARBEC (Marine Biodiversity, Exploitation and Conservation); Bd Jean Monnet; BP

17134203 Sète Cedex France

* Corresponding author : Vincent Rossi, email addresses : vincent@ifisc.uib-csic.es ;

vincent.rossi.ocean@gmail.com

\begin{abstract}
:
Aim

Assessing the spatial structure and dynamics of marine populations is still a major challenge in ecology. The need to manage marine resources from ecosystem and large-scale perspectives is recognized, but our partial understanding of oceanic connectivity limits the implementation of globally pertinent conservation planning. Based on a biophysical model for the entire Mediterranean Sea, this study takes an ecosystem approach to connectivity and provides a systematic characterization of broad-scale larval dispersal patterns. It builds on our knowledge of population dynamics and discusses the ecological and management implications.
\end{abstract}

Location

The semi-enclosed Mediterranean Sea and its marine ecosystems are used as a case study to investigate broad-scale connectivity patterns and to relate them to oceanography and population dynamics.

Methods

A flow network is constructed by evenly subdividing the basin into sub-regions which are interconnected through the transport of larvae by ocean currents. It allows for the computation of various connectivity metrics required to evaluate larval retention and exchange. 
Results

Our basin-scale model predicts that retention processes are weak in the open ocean while they are significant in the coastal ocean and are favoured along certain coastlines due to specific oceanographic features. Moreover, we show that wind-driven divergent (convergent, respectively) oceanic regions are systematically characterized by larval sources (sinks, respectively). Finally, although these connectivity metrics have often been studied separately in the literature, we demonstrate they are interrelated under particular conditions. Their integrated analysis facilitates the appraisal of population dynamics, informing both genetic and demographic connectivities.

\section{Main conclusions}

This modelling framework helps ecologists and geneticists to formulate improved hypotheses of population structures and gene flow patterns and to design their sampling strategy accordingly. It is also useful in the implementation and assessment of future protection strategies, such as coastal and offshore marine reserves, by accounting for large-scale dispersal patterns, a missing component of current ecosystem management.

Keywords : Larval dispersal, local retention, marine connectivity, marine ecosystems, marine protected areas, Mediterranean Sea, population dynamics, population genetics, self-recruitment, source/sink dynamics 


\section{Introduction}

2 Efficient management strategies should be proposed and applied to maintain the values and services of marine ecosystems that are impacted at both regional and global scales by increasing anthropogenic stressors. Such strategies require a global view encompassing the large dimensions of oceanic systems and a good knowledge of complex ecosystem dynamics (instead of mono-specific focus). A good understanding of large-scale biogeography and spatial dynamics of marine populations is thus a prerequisite to scale-up regional management planning and to optimize the conservation of marine ecosystems heterogeneously distributed across large scales.

Marine populations are commonly structured as a "metapopulation" in which discrete "subpopulations" are linked to each other via the exchange of individuals (adults, juveniles, larvae, eggs...) Cowen \& Sponaugle 2009 Calò et al. 2013. This population connectivity (i.e. the exchanges of individuals among subpopulations) can be evaluated with the study of genetic connectivity, defined as the degree to which gene flows affect evolutionary processes within subpopulations. Another closely related concept, often used in conservation plans, is demographic connectivity. It accounts for the impact of dispersal processes on growth and mortality rates of a subpopulation Lowe \& Allendorf 2010]. A good understanding of population connectivity, together with genetic and demographic connectivities, is fundamental for predicting the replenishment of a site after disturbance (population persistence), for the maintenance of biodiversity and overall for the management of marine ecosystems Palumbi 2003; Cowen et al. 2006, Hastings \& Botsford 2006, Cowen \& Sponaugle 2009].

Since movements of adults are quite limited for a great majority of marine species Cowen \& Sponaugle 2009], the exchanges among subpopulations occur primarily through the pelagic dispersion of early life stages (eggs, larvae) transported by ocean currents over large distances Kinlan \& Gaines 2003; Shanks et al. 2003, Gaines et al. 2007; Siegel et al. 2008: Moffitt et al. 2009]. Even for species whose adults are highly mobile (e.g. large pelagic), oceanic circulation can play a crucial role in controlling the success of spawning, dispersal and settlement Reglero et al. 2012, with implications for the structure and conservation of these populations Rodriguez et al. 2013. Indeed, both the magnitude and modality of larval dispersal by ocean currents are theoretically expected to affect both genetic and demographic connectivities. Consequently, studying the transport of larvae with biophysical models and discussing its managerial and genetic implications have received growing interest to delimit hydrodynamical provinces Rossi et al. 2014, to characterize connectivity in various marine environments [e.g. Mitarai et al. 2009; Guizien et al. 2012; Treml et al. 2012, Young et al. 2012; Wood et al. 2014 or to investigate their effect on genetic connectivity Kool et al. 2011; Foster et al. 2012].

Depending on the rate of migration, previous studies simplified the contrasting connectivity occurring in the real ocean by distinguishing open subpopulations that receive/export individuals from/to other subpopulations, „while closed subpopulations do not exchange individuals to an appreciable extent [e.g. Hixon et al. 2002; Pinsky et al. 2012. This implies that open subpopulations are primarily maintained through network persistence (i.e the exchange of individuals with neighbouring subpopulations) while closed subpopulations mainly survive through self-persistence (i.e local birth rate higher than death rate). Another distinction among geographically separated subpopulations that are not completely isolated from each other was introduced by Pulliam 1988 with the concept of Source/Sink dynamics. Habitat heterogeneity and variable dispersal ability lead to different demographic and exchange rates in each subpopulation, having key implications for conservation goals Roberts 1997: Crowder et al. 2000. Estimating the extent to which subpopulations are open/closed or sources/sinks has led to the definition of various local connectivity metrics that are related to larval transport. Particular attention was given to Self-Recruitment $(S R)$, which measures the proportion of all local larval recruits that originated from the source population [e.g. Jones et al. 1999, Planes et al. 2009, Saenz-Agudelo et al. 2011. Other studies estimated the Local Retention $(L R)$ defined as the proportion of local larval production retained on a site Carson et al. 2011; Hogan et al. 2012. Because $S R$ is a function of the number of larvae arriving from elsewhere and $L R$ depends on the number of those leaving, these two metrics do not inform on population connectivity similarly Burgess et al. 2014. Concerning proxies of exchange in the marine realm, Cowen \& 
Sponaugle 2009 defined a source population as a subpopulation in which the net export of individuals is greater than the net import; the reverse is a sink. Since larvae are the most dispersive stage of many marine species, Roberts 1997] proposed to simplify the source/sink character by focusing on the directional movement of larvae in ocean currents. Although this simplification might not hold for all marine species, it was later supported by Bode et al. 2006 who identified source/sink subpopulations primarily driven by larval dispersal and only marginally by local demography.

Despite the crucial information brought by these open/closed and source/sink proxies applied to larval transport, they have not been investigated at large-scale. Furthermore, although they are often employed to describe local subpopulations or to make management recommendations, the link with oceanographic processes and their inter-relationships remain unclear.

In this study we propose a modelling framework to systematically characterize larval dispersal and connectivity at large-scale, providing the necessary information to evaluate their effects on marine populations. Based on a flow network built in the Mediterranean basin, we compute different connectivity metrics inspired from concepts of population dynamics. A series of simulations allows for the analysis of the spatio-temporal variability of these proxies, their links with oceanographic processes and the investigation of their global relationships. While this setting is equally applicable to any target species and to any oceanic area, the general connectivity patterns evidenced here are particularly relevant to several key organisms from Mediterranean ecosystems. Our results are finally discussed in the context of population genetics and ecosystems conservation, with implications for ecologists, biogeographers and managers.

\section{Materials and Methods}

\subsection{Lagrangian flow network}

To study large-scale connectivity patterns, we simulated the dispersal of free-swimming larvae by ocean currents using the Lagrangian Flow Network methodology which is briefly described here while further details are found in Rossi et al. 2014, Ser-Giacomi et al. 2015.

A Lagrangian model simulates passive particle trajectories in the upper-ocean through the off-line integration of the surface velocity field produced by an operational hydrodynamical model at $1 / 12^{\circ}$ horizontal resolution over years $2002-2011$ Oddo et al. 2009. The surface ocean was divided into 3270 equal-area boxes of $1 / 4^{\circ}$ horizontal-resolution (Fig. SI-6). For each experiment, 500 Lagrangian particles were seeded evenly in each box, so that about 1635000 trajectories were computed with a Runge-Kutta 4 algorithm with two parameters: the starting time $t_{0}$ and the time of integration $\tau$ which simulate respectively the period of spawning and the Pelagic Larval Duration (PLD). We retained two PLDs of 30 and 60 days and both winter and summer spawning by considering three successive starting times $t_{0}$ for each season $\left(t_{0}=1^{\text {st }}, 15^{\text {th }}\right.$ and $31^{\text {st }}$ of January and $t_{0}=1^{s t}, 15^{t h}$ and $31^{\text {st }}$ of July) to account for episodic and variable spawning events. A total of 120 numerical experiments (6 starting times over 10 years for 2 PLDs) allows the analysis of robust basin-scale connectivity patterns, focusing on species with a wide geographical range and potential for large-distance dispersal (see additional references in Appendix 1 and Table SI-1 Appendix 3).

Marine populations are not uniformly distributed and panmictic but are rather organized as a network of discrete subpopulations whose persistences depend strongly on self-replenishment and asymmetric exchanges of individuals among heterogeneously distributed habitat patches Kool et al. 2013]. Assuming those exchanges occur mainly during the larval phase, each box (i.e. hereafter "node" of our flow network) can be seen as a discrete habitat which supports the long-term survival of a local subpopulation through larval retention and exchange with its neighbours. 
a)

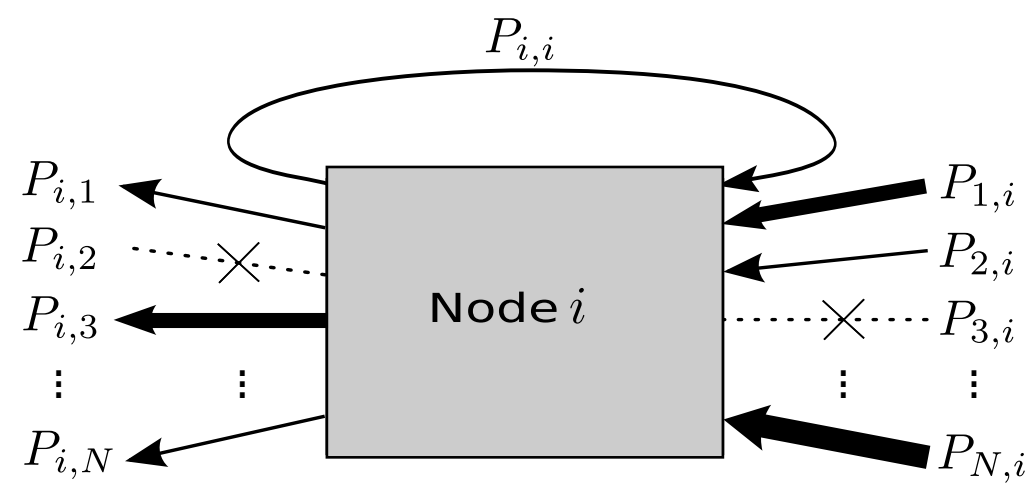

b)

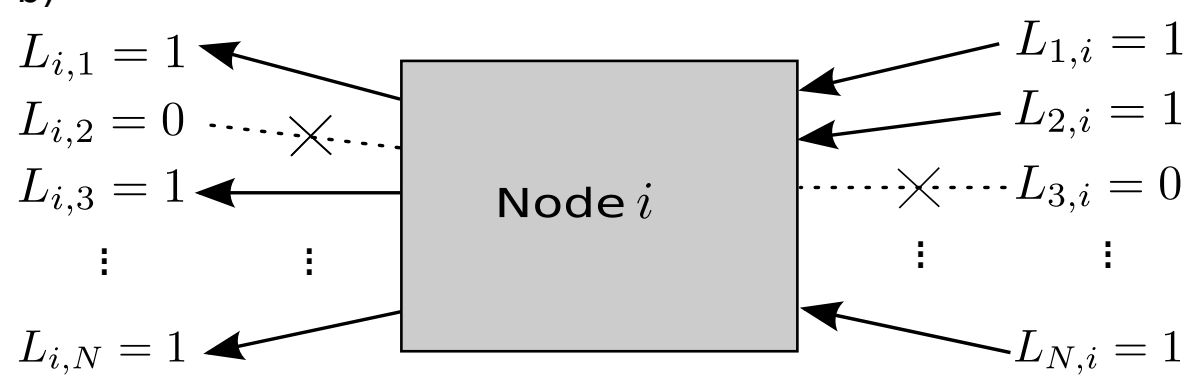

Figure 1: Schematic representation of larval exchanges through a node. (a) The elements $P_{x, y}$ constitute a matrix of larval fluxes used to compute the strength variables (i.e. from the amount of exchanged larvae). (b) The elements $L_{x, y}$ constitute a binary matrix used to compute the degree variables (i.e from the number of connections, independently of their weights). Notations are consistent with the main text.

\subsection{Definition and computation of connectivity metrics}

Our weighted and directed network is analyzed from its adjacency matrix, an equivalent of the connectivity matrix, to describe both the pathways and fluxes of larvae between all sub-areas of the surface ocean. Each element of the connectivity matrix $P_{i, j} \in[0,1]$ represents the probability that a particle released at $t_{0}$ from node $i$ settles in node $j$ after the integration time $\tau$. A diagonal element of the matrix represents the probability that a particle released from node $i$ stays or returns at the same location after integration. The non-diagonal elements represent the transport probabilities between each pair of nodes, considering the origin (destination) node as a row (column, respectively) of the connectivity matrix. Similarly, one can build a simplified binary connectivity matrix $L$ with elements $L_{i, j}=0$ if $P_{i, j}=0$ (i.e. no larval flow from node $i$ to $j$ ) and $L_{i, j}=1$ when $P_{i, j} \neq 0$ (Fig. 1).

A number of studies were based on matrices which only depicted the connectivity between various coastal sites or MPAs [e.g. Treml et al. 2012, Andrello et al. 2013, Mitarai et al. 2009] or among shelf regions [e.g. Nilsson-Jacobi et al. 2012. In contrast, we aim to provide a global framework for the integrative management of both coastal and pelagic ecosystems. While Rossi et al. 2014 studied the global properties of the network to unveil hydrodynamical provinces organizing basin-scale larval dispersal, here we focus on local (node-scale) features to describe larval retention and exchange. For each node, one can examine the number (degree) and weight (strength) of all links emanating from it, referred to as the OUT-degree and OUT-strength, and those arriving in it, called the IN-degree and IN-strength (Fig. 1).

Botsford et al. 2009 defined the Local Retention $(L R)$ as the ratio of locally produced settlement to local larval release. Since the local larval release and the success of recruitment are here assumed to be homogeneous in space, $L R$ can be approximated for each node by the proportion of locally retained particles (i.e. diagonal 
elements of $P$ ):

$$
\text { Local Retention }_{i}=L R_{i}=P_{i, i} \in[0,1] .
$$

Botsford et al. 2009 defined the Self-Recruitment $(S R)$ as the ratio of locally produced settlement to the overall settlement. With our assumptions, $S R$ corresponds to the ratio of retained particles in each box to the total incoming particles from all origins (including those produced locally):

$$
\text { Self-Recruitment }_{i}=S R_{i}=\frac{P_{i, i}}{\sum_{x=1, x \neq i}^{N}\left(P_{x, i}\right)+P_{i, i}}=\frac{P_{i, i}}{\sum_{x=1}^{N}\left(P_{x, i}\right)} \in[0,1] .
$$

For each node, we also compute the local OUT-strength (IN-strength) which measures the proportion of particles released (arriving) locally that were transported (originated from, respectively) elsewhere. It is calculated by summing the rows (columns, respectively) of the connectivity matrix, excluding the diagonal element:

$$
\text { OUT-strength } h_{i}=\text { OUT } T_{i}^{s}=\sum_{x=1, x \neq i}^{N}\left(P_{i, x}\right)=\sum_{x=1}^{N}\left(P_{i, x}\right)-P_{i, i},
$$

$$
I N \text {-strength }{ }_{i}=I N_{i}^{s}=\sum_{x=1, x \neq i}^{N}\left(P_{x, i}\right)=\sum_{x=1}^{N}\left(P_{x, i}\right)-P_{i, i} .
$$

The IN-degree and OUT-degree were computed similarly as the "strength" case but using the binary connectivity matrix $L$ :

$$
\text { OUT-degree }_{i}=O U T_{i}^{d}=\sum_{x=1, x \neq i}^{N}\left(L_{i, x}\right)=\sum_{x=1}^{N}\left(L_{i, x}\right)-L_{i, i},
$$

$$
I N \text {-degree }_{i}=I N_{i}^{d}=\sum_{x=1, x \neq i}^{N}\left(L_{x, i}\right)=\sum_{x=1}^{N}\left(L_{x, i}\right)-L_{i, i} .
$$

Following the simplification of Roberts 1997]; Bode et al. [2006], we finally examine the relative importance of larval export versus import to characterize the local source/sink dynamics. The Source Sink $(S S)$ metrics are defined by:

$$
\text { Source Sink-strength }{ }_{i}=S S_{i}^{s}=\frac{I N_{i}^{s}}{I N_{i}^{s}+O U T_{i}^{s}} \in[0,1] .
$$

$$
\text { Source Sink-degree } e_{i}=S S_{i}^{d}=\frac{I N_{i}^{d}}{I N_{i}^{d}+O U T_{i}^{d}} \in[0,1] .
$$

They evaluate the source or sink character, in terms of the total amount of larvae (strength) or in terms of the spatial diversity of origins and destinations (degree). These metrics are restricted between 0 and 1 by construction and their negative (positive) deviations from 0.5 allow the quick appraisal of the nodes behaving as sources (sinks, respectively).

\subsection{Spatio-temporal variability}

Spatial patterns of each connectivity metric over the entire Mediterranean basin (Fig. SI-4) are studied through the mapping of their local (node-by-node) time-averages across all 120 simulations. Considering the intra-annual variability of the Mediterranean circulation [e.g. Bakun \& Agostini 2001; Pinardi \& Masetti 2000] (see also Fig. SI-5), we investigate how these spatial patterns change with the spawning season. To do this, we compute temporal averages over a subset of the simulations considering the two seasons separately.

To evaluate the confidence of the averages reported on the maps, we calculate the standard deviation $\sigma$ of our local metrics and we then relate the variance $\sigma^{2}$ to the temporal mean $\mu$ by means of the so-called $i$ ndex of dispersion. The local mean is considered non-informative if $\sigma^{2} / \mu>0.5$ (see pink crosses on Fig. 2, 3, 44). 


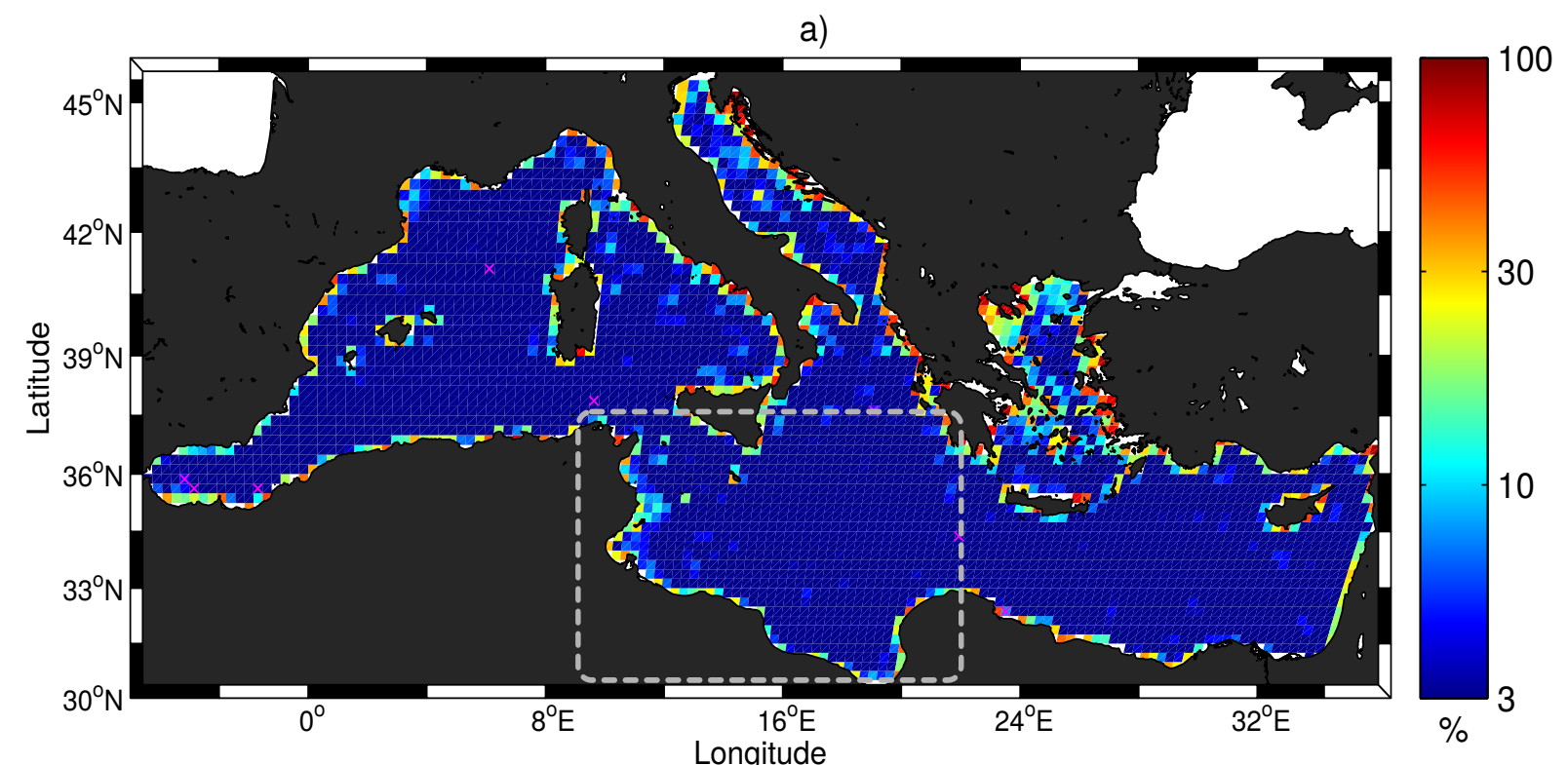

b)
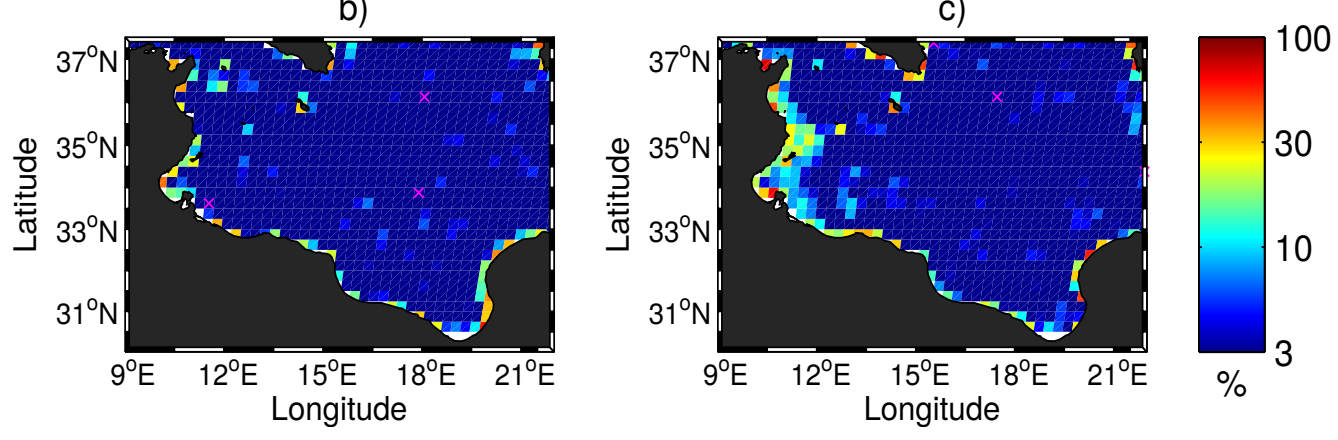

Figure 2: (a) Mean Local Retention $(L R)$ for a Pelagic Larval Duration (PLD) of 30 days averaged across 60 (winter and summer) connectivity matrices; (b) mean $L R$ over the southern Ionian Sea averaged across 30 winter matrices and (c) 30 summer matrices. Pink crosses in some boxes indicate particularly large temporal variability $\left(\sigma^{2} / \mu>0.5\right)$. For color version of this figure, the reader is referred to the online version of the article.

Nodes with a particularly high temporal variability are indicative of oceanic regions where the stochasticity of the circulation does not permit a robust characterization of connectivity.

\section{Results}

\subsection{Global connectivity metrics}

The global distributions of our connectivity metrics and their robustness to the most relevant biological and physical parameters have been investigated in Appendix 2 (Fig. SI-1 to 3). In particular, our results are insensitive to the scale of spatial discretization (Fig. SI-2) and to the initial density of particles (Fig. SI-3).

\subsubsection{Mapping retention metrics}

Despite significant variability, maps of mean $L R$ and $S R$ over the Mediterranean basin (Fig. 2 ) reveal strongly contrasted patterns of retention rates. The largest $L R$ or $S R(>30 \%)$ are observed along the continental and insular coastlines while moderate values $(10 \%<L R$ or $S R<30 \%)$ are also found slightly offshore in nodes located over the continental shelf (depths $<200 \mathrm{~m}$ ). In contrast, most open ocean boxes (depths $>200 \mathrm{~m}$ ) show on average null or very low $(>1 \%) L R$ or $S R$ (Fig. 2a). 
While these global patterns are observed for all simulations, some seasonal differences are noticeable. For instance, elevated values of $L R$ and $S R$ are found over the Tunisian shelf during summer whereas they are more restricted to the near-coastal boxes in winter (Fig. $2 \mathrm{~b}$ and c).

\subsubsection{Mapping Source/Sink metrics}

All $\sigma$ computed over 60 (global mean; Fig. 3) or 30 (seasonal mean; Fig. 4) connectivity matrices are of the same order of magnitude for both PLDs and reveal that less than $1 \%$ of nodes have $\sigma^{2} / \mu>0.5$. Their locations do not show any consistent pattern, except in the western Alboran Sea which has thus been disregarded from our analyses 1 .

SS-degree and SS-strength show relatively similar spatial patterns (Fig. 3), with a slightly smaller magnitude for larval sinks in the SS-strength variable ${ }^{2}$. This holds true for both PLDs (not shown). As such, we only analyze the patterns observed in both $S S$-degree and SS-strength using a PLD of 60 days (as longer dispersal tends to accentuate patterns of exchange, see also sect. 3.1 and SI sect. 1).

Some regions are characterized by relatively stable behaviour throughout the year. For instance, larval export (source) is observed over most of the Ligurian Sea, intensified in near-shore areas (Fig. 3). The Gulf of Lion can be divided into two sub-regions: the north-east gulf which behaves as a larval source and the south-western coastlines which act as sinks. This "dipole" pattern is clearly visible in SS-degree (and to a lesser extent in SS-strength) and is similar for both seasons (Fig. 3), with the greatest differences observed during winter (Fig. 4a, b). The Adriatic Sea has a persistent larval sink along the southern Italian shores (Puglia coasts and the gulf of Taranto). Coastlines of Lybia, Egypt, Israel and Lebanon behave primarily as larval sinks throughout the year (Fig. 3), with an intensification along the Egyptian coastlines in summer (Fig. 44a, c).

Others regions are marked by two very distinct seasonal patterns. For instance, during summer most of Balearic Sea behaves as a quite homogeneous larval sink (Fig. 4 4 , b), whereas it shows disparate sources and sinks in winter. The northern Ionian Sea and the coastlines of Calabria and Sardinia behave as sources during winter while the western Greek shores are sinks (Fig. 4 4). During summer, there is the opposite situation. The same pattern is observed in the Aegean Sea (Fig. 4a, c): in winter its eastern side acts as a larval sink while its western side is a source. The reverse is observed in summer. At smaller-scales, the Gulf of Taranto in wintertime acts as a sink on its north-eastern coast and as a source on its south-western side but it appears as a strong sink in summer (Fig. 4 a, c).

Finally the central Ionian Sea, central Levantine Sea and Algerian Basin are characterized by heterogeneous patterns of both SS-degree and SS-strength (Fig. 3), with a particularly weak signal close to 0.5, making it difficult to discern clear sources or sinks in these open ocean regions.

\subsection{Relationships among connectivity metrics}

When we plot $L R$ versus $S R$ considering each box and each simulation independently, we find a rather loose relationship (Fig. 5a) with a correlation coefficient $R^{2}$ of 0.69 , indicating a significant spread of the variables. However, by locally averaging $L R$ and $S R$ over all simulations (for a fixed PLD), they appear positively correlated through a more compact linear relationship (Fig. 5b). In this case, the $R^{2}$ coefficient is 0.89 , suggesting that $L R$ and $S R$ are on average nearly equal at a given site (under our assumptions of homogeneous larval production and mortality).

To investigate if there is a global relationship between retention and exchange metrics we distinguished each point of the $L R$ versus $S R$ scatterplots according to its value of $S S$-degree and $S S$-strength (Fig. 6). We find that a sink site $(S S \leq 0.4)$ tends to have higher $L R$ than $S R$ whereas a source site $(S S \geq 0.6)$ is characterized

\footnotetext{
${ }^{1}$ This "edge effect" is due to the lack of constant particle seeding despite the continuous entrance of Atlantic water through the Gibraltar strait.

${ }^{2}$ This maybe due to the almost incompressible character of the surface velocity field at these short time-scales.
} 
a)

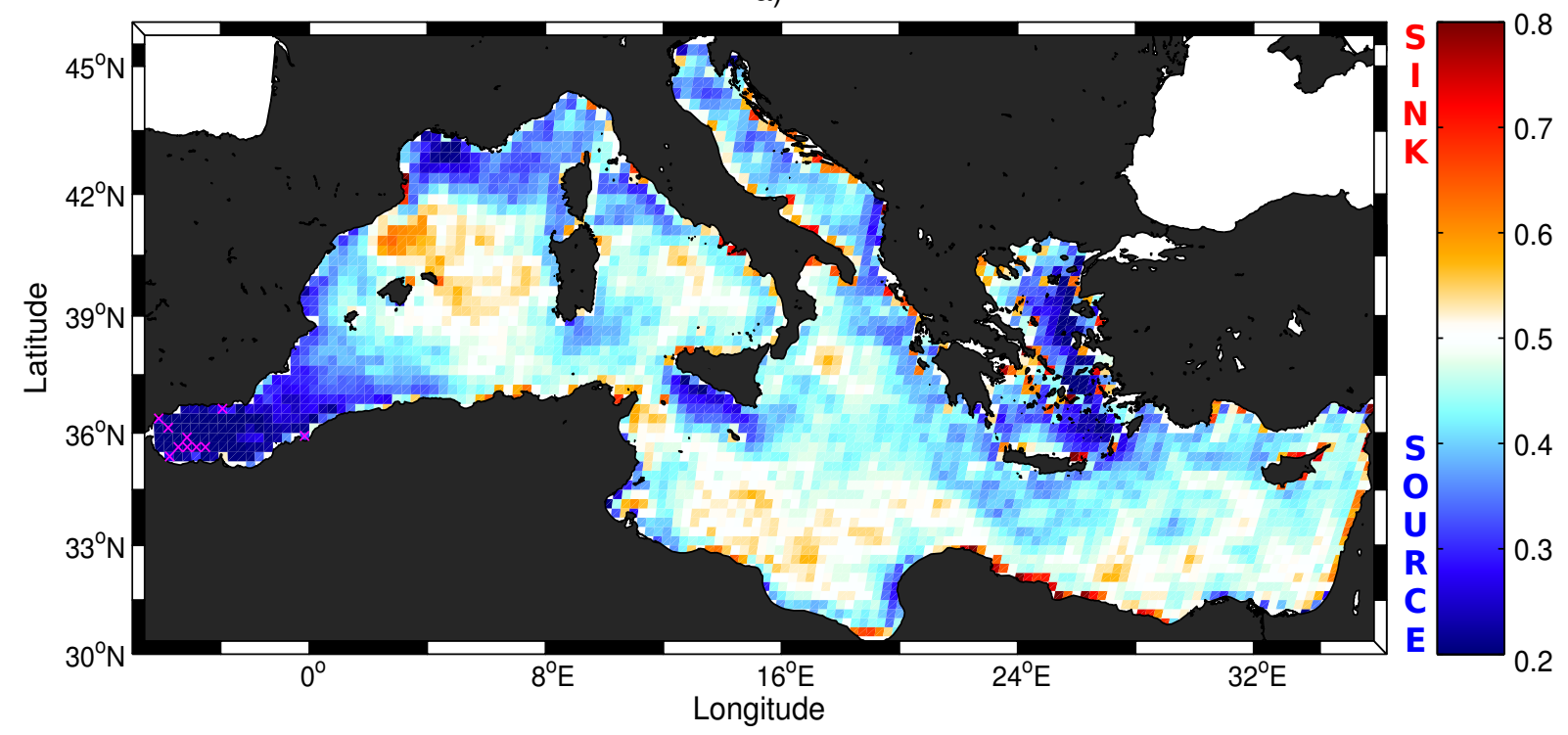

b)

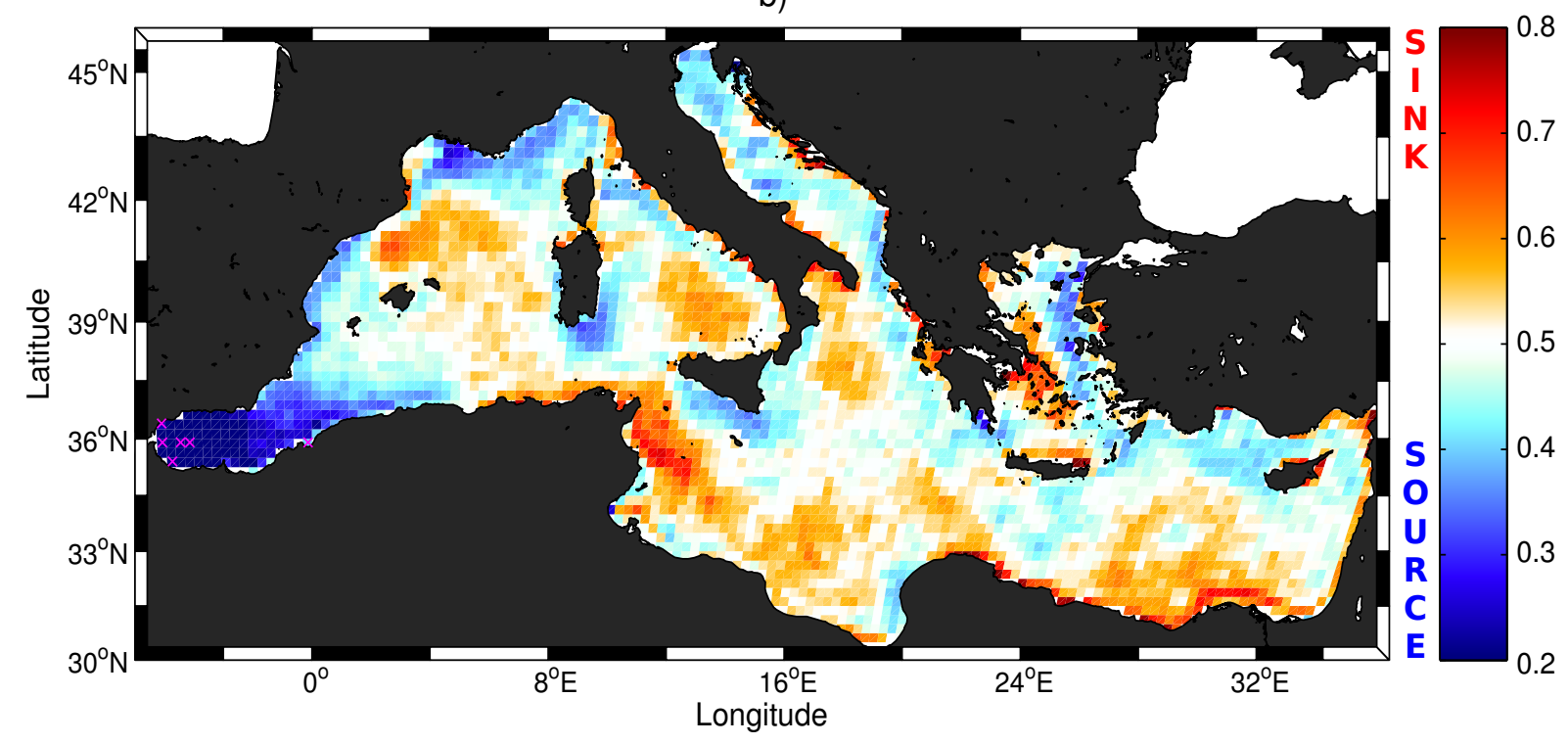

Figure 3: (a) Mean Source Sink-strength (relative importance of larval export versus import, computed from larval fluxes following Eq. [7]) and (b) mean Source Sink-degree (relative importance of larval export versus import, computed from the numbers of links independently of their weights following Eq. 8]) averaged across 60 (winter and summer) connectivity matrices for a PLD of 60 days. Pink crosses in some boxes indicate particularly large temporal variability $\left(\sigma^{2} / \mu>0.5\right)$. For color version of this figure, the reader is referred to the online version of the article. 


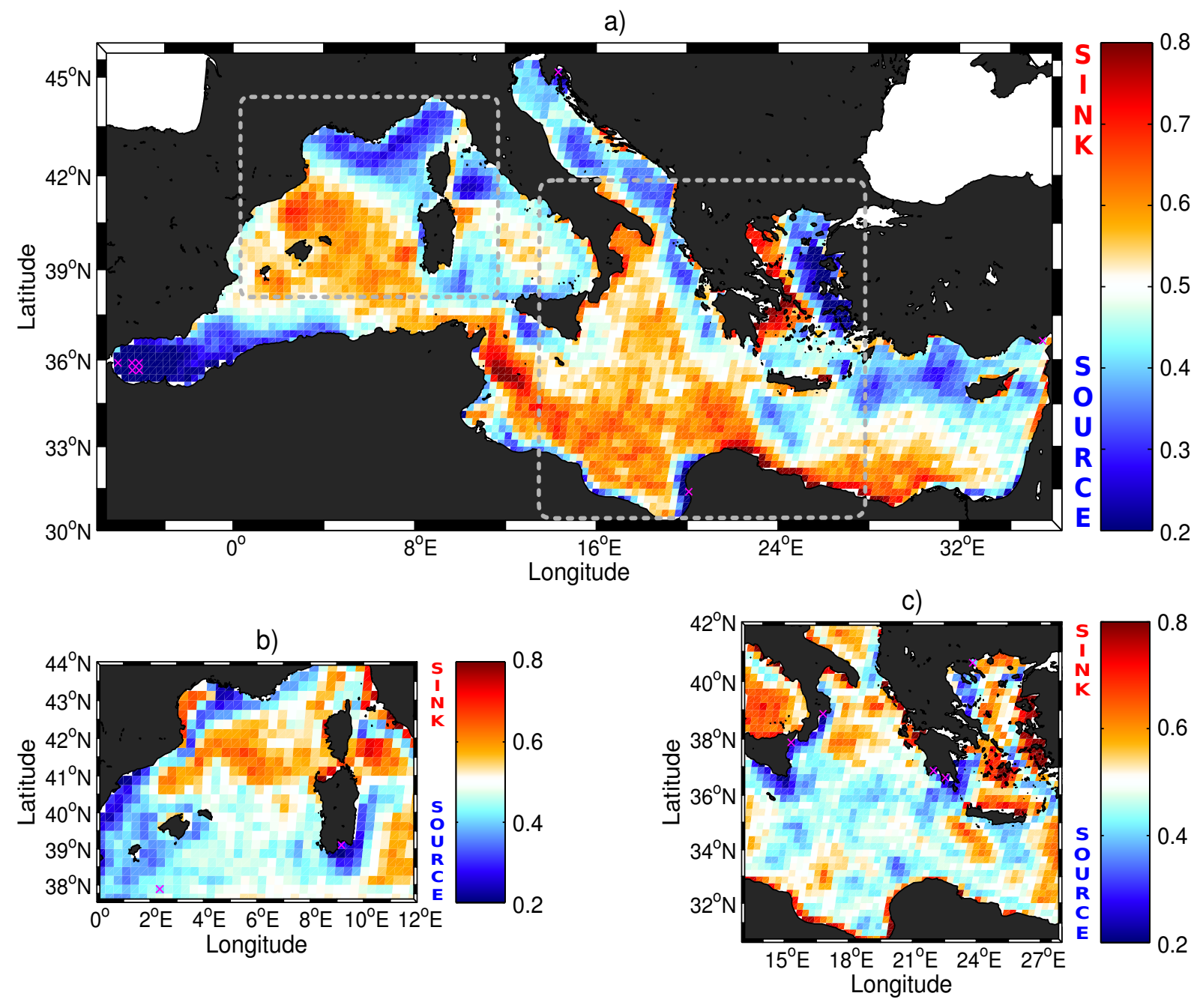

Figure 4: (a) Mean Source Sink-degree (relative importance of larval export versus import, measuring the number of links) averaged across 30 summer matrices and averaged across 30 winter matrices (b) over the north-west Mediterranean and (c) over the Ionian Sea for a PLD of 60 days. Pink crosses in some boxes indicate particularly large temporal variability $\left(\sigma^{2} / \mu>0.5\right)$. For color version of this figure, the reader is referred to the online version of the article. 
a)

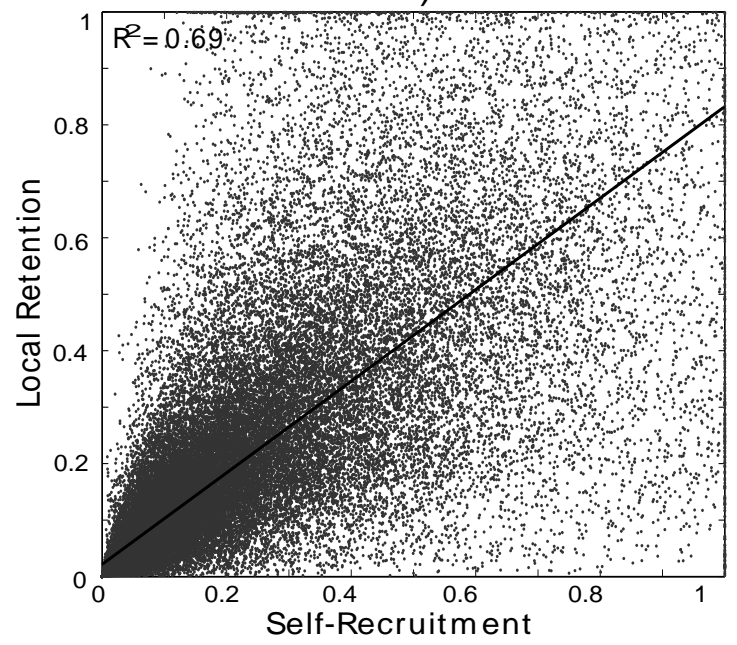

b)

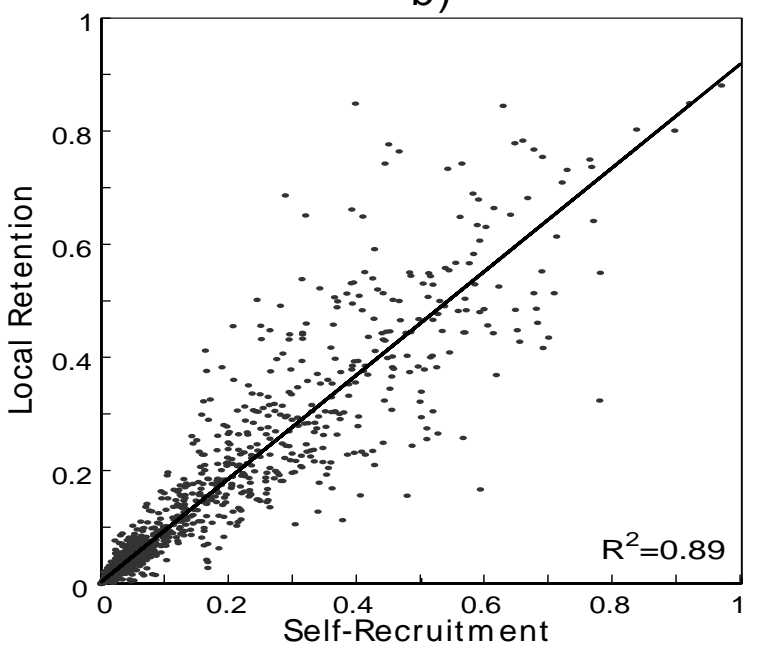

Figure 5: Relationship between LR (Local Retention) and SR (Self-Recruitment) for a PLD of 30 days when (a) considering each node (3270) and each simulation (60) independently, and (b) when averaging our proxies locally across all simulations.

by $S R$ higher than $L R$. A tight linear relationship between $S R$ and $L R\left(R^{2}\right.$ of 0.96$)$ is found for the sites characterized by neutral $S S$ (i.e. with similar larval import and export $0.4 \leq S S \leq 0.6$ ).

\section{Discussion}

\subsection{Linking broad-scale connectivity patterns and oceanography}

From a basin-scale perspective, our study highlights common oceanographic conditions which would favour retention processes in any oceanic region. Extended continental shelves and complex bathymetry (e.g. islands, capes, large bays, Fig. SI-4) in association with relatively weak currents (Fig. SI-5) lead to high retention near the coast. Specific locations of enhanced $L R$ and $S R$ are the Gulf of Lion, the Gulf of Valencia/Ebro delta, the Tuscan archipelago, the Croatian coastlines and the insular and near-shore sub-regions of the Aegean Sea. This is consistent with the elevated retention processes that were documented in coral reef environments using high resolution biophysical models [e.g. Paris \& Cowen 2004 Treml et al. 2012. Retention is however diminished by large-scale energetic currents flowing close to the shore (e.g. the narrow continental shelves of the french "Côte d'Azur") and by long-lived mesoscale structures travelling offshore (e.g. the Algerian coast). The seasonal change of $L R$ or $S R$ observed over the Tunisian shelf illustrates clearly these two behaviours (Fig. 2p, c). The high $L R$ observed in summer decreases during winter due to the acceleration and intrusion over the shelf of the Sicily-Strait-Tunisian-Current Millot \& Taupier-Letage 2005 (Fig. SI-5).

The variability of $S S$-degree and $S S$-strength metrics appears also primarily determined by the oceanographic setting as most larval sources (sinks) identified here match well-known divergence (convergence) zones. For instance, the "sink" character of the Balearic Sea could be related to the dominant wind regimes that forces convergent surface transport and downwelling in the centre of the gyre, especially in summer Bakun \& Agostini 2001]. In contrast, atmospheric patterns change during winter with the intensification of the Cierzo wind in the Ebro valley, resulting in a cyclonic wind stress curl producing an area of Ekman divergence and associated upwelling Bakun \& Agostini 2001] in the southern part of the Balearic Sea. The permanent retentive character of the north-eastern Balearic Sea is consistent with the results of Poulain et al. 2012 who documented the highest residence times of geolocated surface drifters in this area over the last decade. Offshore sources such as 
a)

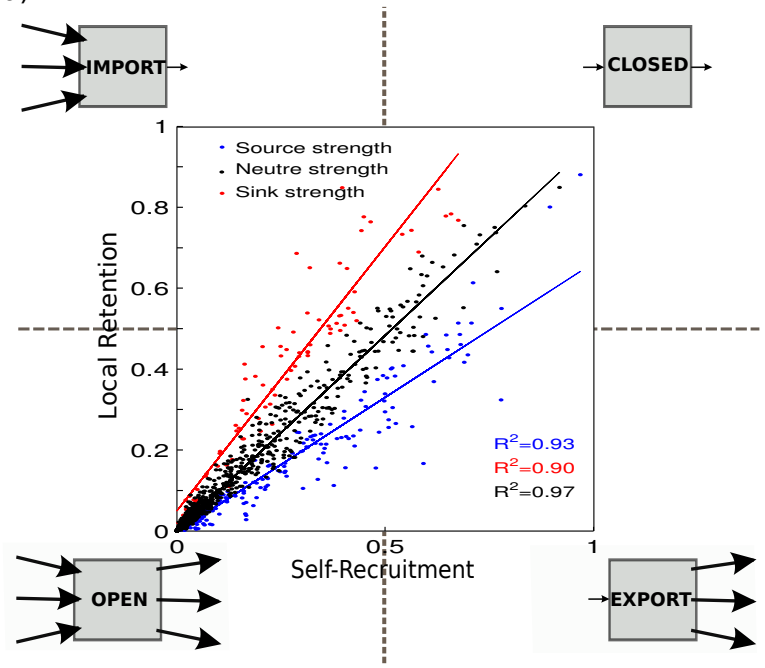

b)

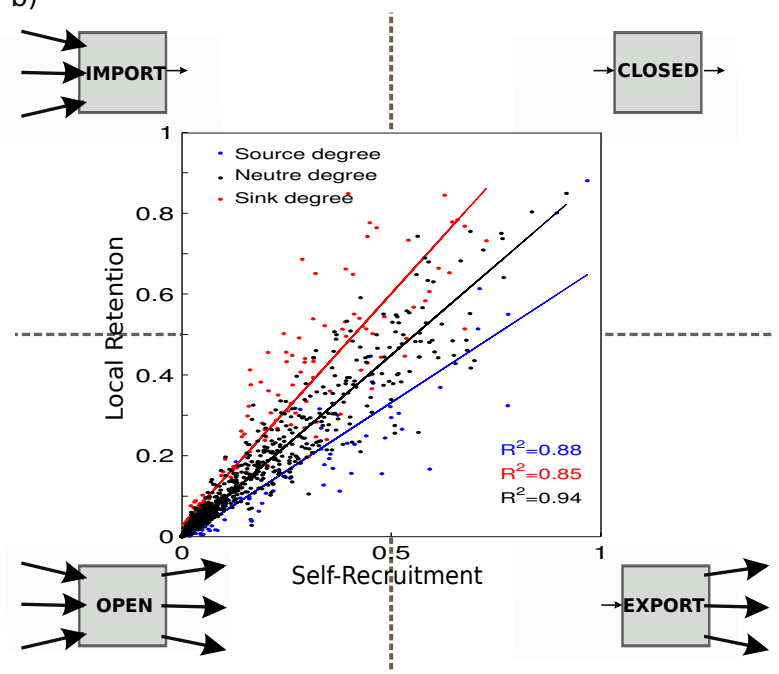

Figure 6: Inter-relationship among connectivity metrics for a PLD of 30 days. Mean relationship between $L R$ (Local Retention) and $S R$ (Self-Recruitment) distinguishing "source" (blue), "sink" (red) and "neutral" (black) nodes based on (a) $S S$ - strength (Source-Sink index computed from larval fluxes) and (b) $S S$ - degree (Source-Sink index computed from the number of links). Annotations represent schematically the behaviour of a node according to its location on the plot. Source (sink) nodes are characterized by $S S-$ strength or $S S$-degree smaller than 0.4 (larger than 0.6 , respectively). For color version of this figure, the reader is referred to the online version of the article.

in the Adriatic and Tyrrhenian Sea are also reasonably well explained by the oceanographic context with the three cyclonic gyres in the Adriatic Sea and the summer strengthening of the northern Tyrrhenian cyclonic gyre (Fig. SI-5). Whereas the larval sinks observed along the Lybian/Egyptian shores are due to the dominance of coastal convergence all year long Bakun \& Agostini 2001.

The impact of a boundary current on connectivity properties is another relevant mechanism that is clearly evidenced in the north-western Mediterranean. The dominant circulation pattern in the region is the LiguroProvençal Current (Ligurian sector) which extends into the Northern Current off the Gulf of Lion (Fig. SI-5). It intensifies and narrows during winter [Millot \& Taupier-Letage 2005] which would favour larval export along the main axis of the jet. This provides a good explanation for the narrow larval source observed in winter along the French coastline as well as the blue vein (source) further west that sharply separates the Gulf of Lion from the Balearic Sea. In contrast, during summer the source region (Ligurian Sea) extends further offshore due to the slower and less defined current associated with the "Mistral" wind which tends to veer eastward, forcing coastal upwelling Bakun \& Agostini 2001.

The Gulf of Lion is characterized by a shallow bathymetry that often maintains the core of the Northern Current off the shelf-break. As such, the inner-shelf circulation is primarily influenced by the "Tramontane" and "Mistral" winds which produce a divergent zone associated with upwelling along the Provence/Camargue coastlines (north-eastern parts of the Gulf) and a convergent zone with downwelling along the Languedoc-Roussillon coast (south-western parts of the Gulf) Millot \& Taupier-Letage 2005. These divergence/convergence zones are closely aligned with the source/sink dynamics previously described. Note that the accentuated source/sink pattern observed in the Gulf during winter is also consistent with the seasonal intensification of "Mistral" and "Tramontane" winds Bakun \& Agostini 2001. Similarly, other "dipoles" of upwelling/downwelling forced by seasonal wind regimes are in agreement with our proxies (Fig. 3. 45: for example the source/sink dipole documented along the northern Ionian and Aegean coastlines Pinardi \& Masetti 2000 and the winter dipole observed in the Gulf of Taranto Bakun \& Agostini 2001.

Although relatively stable circulation is consistently associated with larval sources/sinks, it is worth mentioning that some regions such as the central Levantine Sea and the Algerian Basin are characterized by chaotic 
and turbulent transport Millot \& Taupier-Letage 2005, Poulain et al. 2012 preventing a clear depiction of their connectivity patterns.

\subsection{Unifying hydrodynamic and genetic connectivity}

Despite numerous attempts to characterize the interplay between the complex life history traits of marine organisms, their distribution ranges and their realized dispersal [e.g. Riginos et al. 2011, Mora et al. 2012, the respective roles of intrinsic and extrinsic factors that determine population connectivities remain unclear Botsford et al. 2009. Previous research revealed that the relationship between PLDs and geographic distances alone have a limited influence, if any, on observed genetic structuring [e.g. Weersing \& Toonen 2009; Riginos et al. 2011, calling for a better appraisal of biological and extrinsic factors, such as hydrodynamics, that drive both species range and population connectivity [e.g. Baums et al. 2006; Jolly et al. 2009; White et al. 2010, Schunter et al. 2011; Kool et al. 2011; Soria et al. 2012; Foster et al. 2012.

Through the direct incorporation of population genetic concepts into a bio-physical modelling approach at basin-scale, we propose a common framework for geneticists and oceanographers to explore connectivity issues Botsford et al. 2009]. Our results, and more generally the tunable modelling framework proposed here, should allow i) to formally test the effects of specific oceanographic processes on population genetics by integrating the most relevant biological traits for a group of species into this general framework and ii) to target sub-regions with dissimilar connectivity behaviours as predicted here, whose effects on connectivity in relation with species distributions and life history traits could be evaluated.

As shown by Thomas \& Bell [2013], the persistent larval sources/sinks that we identified have the potential to impact the genetic connectivity of local subpopulations. For instance, the genetic homogeneity found among the sea-bream Diplodus sargus populations of the Italian, French and Spanish coasts Lenfant \& Planes 1996 could be related to the efficient gene flows occurring among those source areas. In contrast, genetic samples originating from the south-western part of the Gulf of Lion were found differentiated from the surrounding areas for D. sargus Lenfant \& Planes 1996 and the sessil red gorgonian Paramuricea clavata Mokhtar-Jamaï et al. 2011]. A strong influence of oceanographic features on larval dispersal was hypothesized to explain the genetic differentiation observed in the south-west Gulf. This was later supported by a small-scale study Guizien et al. 2012 as well as by our basin-scale model, both predicting a marked larval sink in this region. It is important to note that with our assumptions, which differ from those of Pulliam 1988, a subpopulation is characterized as a sink under two contrasting situations. On one hand, a subpopulation is classified as a sink when it sends almost no emigrant elsewhere (i.e. weak exportation, high $L R$ ), suggesting it is mainly genetically influenced by itself and that significant levels of genetic differentiation with its neighbouring subpopulations may be established Jolly et al. 2009. On the other hand, a sink is also identified when importation from neighbouring source(s) are particularly high (i.e. low $S R$ ), that would suggest potential inputs of genetic materials from surrounding subpopulations and could possibly result in weak genetic differentiation between the connected source/sink subpopulations Gaggiotti 1996]. Such sink subpopulations could be further distinguished into those influenced by a single or by several sources, potentially maximizing its genetic diversity Pannell \& Charlesworth 1999. Indeed subpopulations of the Balearic Sea have been often described as a "mixed genes pool" with diverse genetic influences from the Alboran, Catalan and Ligurian seas Ledoux et al.|2010, Mokhtar-Jamaï et al.|2011]. Our results consistently suggest that the Balearic Sea is a basin of attraction for drifting larvae as evidenced by a strong influx (strength) from diverse origins (degree), potentially leading to a mixture of local genes and those from the surrounding sources. 


\subsection{Interpretation of connectivity metrics for management purposes}

As recently shown by Lett et al. 2015 (by using a metapopulation model combined with genetic data of SaenzAgudelo et al. 2011]) and the genetic study of Hogan et al. 2012, we confirm $S R$ is a good predictor of $L R$, especially when averaging the stochasticity of ocean currents.

Our models demonstrate that $L R$, which is a crucial parameter to infer population persistence but is rather hard to access Burgess et al.2014], can be reliably estimated for "neutral" subpopulation through $S R$, generally much easier to measure through empirical approaches. However, when a population is characterized by large relative differences between its exportation and importation, $L R$ and $S R$ are still linearly correlated but with a slope $>1$ for sinks and $<1$ for sources. This is because a site characterized by high $S R$ (i.e. low "Openness" Hixon et al. 2002]) rarely receives larvae from elsewhere (weak import) and inversely, a site with high $L R$ would have very low exportation. Consequently, a subpopulation with both high $S R$ and $L R$ can be considered as "closed" due to the limited upstream and downstream exchanges, while "open" subpopulation would be characterized by low rentention rate (Fig. 6). In other words, the greater the relative difference between $S R$ and $L R$, the larger are the deviations of SS-degree or SS-strength from 0.5, and the more pronounced is the source or sink behaviour. While these conclusions based on SS-strength are straightforward, we also show they hold when considering $S S$-degree: a site which tends to import from distinct geographical regions but export to only a few (a sink in terms of degree) is also characterized by $L R$ higher than $S R$, which would have consequences for the local genetic and phenotypic diversities.

The integrated interpretation of retention and exchange large-scale connectivity indices has implications for the implementation of coastal and pelagic Marine Protected Areas (MPAs). They give insight into how subpopulations are connected through larval transport and as such, help to predict the effects of management measures or disturbances on both local and surrounding subpopulations. For instance, establishing a MPA on a site whose larval supply originates from several non-protected "upstream" subpopulations may be ineffective Roberts 1997, Crowder et al. 2000, especially if retention rates are not sufficient to allow for self-persistence of source sub-populations. Another strategy could be to position new MPAs within regions characterized by both significant retention and exchange of larvae, thus favoring together self- and network persistence. Overall, an accurate depiction of both local and broad-scale connectivity, as is allowed by our model, is necessary to appropriately implement MPAs.

\subsection{Modelling limitations and future developments}

Rather than developing a realistic model for a single species [e.g. Kool et al. 2011, Foster et al. 2012], we retained a range of parameters in accord with well-known ecological traits of various Mediterranean organisms to describe large-scale connectivity patterns from an Ecosystem Approach. The "true" connectivity of marine populations depends however on numerous species-specific biological processes such as the production of larvae, its swimming behaviour, its natural mortality, the duration of the pelagic phase (PLD), the success of recruitment, the trophic interactions, etc., all of which are also influenced by abiotic factors such as the variable oceanic circulation and the heterogeneity of littoral and pelagic habitats Cowen \& Sponaugle 2009. Despite resolving only some of these processes, we highlight specific oceanographic processes that control larval connectivity, potentially affecting both demographic and genetic connectivities of many marine organisms. Furthermore, it is worth emphasizing that this modelling framework is indeed adaptable to any species whose biological traits and ecological preferences are precisely known.

For instance, homogeneous larval production in both coastal and open ocean regions is a strong assumption since some organisms spend most of their life-cycle in shallow areas (Tab. SI-1). Nevertheless, our source/sink metrics can be re-calculated to restrict larval release over the continental shelves by selecting only the corresponding nodes within the full connectivity matrices (Fig. SI-6). In this case, very similar spatial patterns are observed (Fig. SI-7), suggesting that offshore processes only marginally affect the connectivity of continental 
shelves Rossi et al. 2014. One could also incorporate the effects of habitat patchiness on population connectivity Pinsky et al. 2012, Anadón et al. 2013 by adjusting local larval production and success of recruitment according to the proportion of favourable habitat in each node.

Realistic larval traits, such as active swimming, could be also implemented, but only large vertical migrations (outside of the surface mixed layer) are expected to significantly change the dispersal schemes Corell et al. 2012. Nevertheless, little information exists about the behaviour and the spatial distribution of larvae of most organisms Calò et al. 2013, and even when it is relatively well-known, Treml et al. 2012 found little impact of biological parametrizations on broad-scale connectivity. Lastly, although near-shore areas are not particularly well resolved by the basin-scale model we used, most patterns are in agreement with regional studies based on dedicated high-resolution models [e.g. Guizien et al. 2012 .

\section{Conclusions}

Describing the connectivity of marine subpopulations, thought to be governed largely by the dispersal of pelagic larval stages, has ecological and managerial implications. We propose a modelling framework including Lagrangian simulations, tools from Network Theory and concepts of population dynamics to characterize marine connectivity at basin-scales. Various connectivity metrics and their spatio-temporal variability are related to local oceanography. We show that retention processes are favoured along coastlines with sluggish circulation and over extended continental shelves. We also demonstrate that convergence/divergence areas generated by alongshore winds are often associated with larval sinks/sources. Furthermore, studying the relationship among the connectivity metrics sheds light on their integrated interpretation for conservation planning. Overall, our results offer opportunities to (i) improve the sampling strategy of genetic studies, (ii) formulate and test hypotheses pertaining to the role of larval dispersal in the spatial and genetic structuring of populations and (iii) systematically depict retention and transport processes at multiple scales, which is propitious to their adequate consideration in the management of marine ecosystems.

\section{Acknowledgements}

The authors acknowledge supports from MINECO/FEDER through the ESCOLA project (CTM2012-39025C02-01), from ECs Marie-Curie ITN program (FP7-PEOPLE-2011-ITN) through the LINC project (289447) and from MISTRALS ENVI-Med through the HYDROGENCONNECT project. The simulated velocity field used in this study was generated by MyOcean (now Copernicus, www.marine.copernicus.eu). V.R. and M.D acknowledge E. Boissin, P. Reglero, D. Alvarez-Berastegui, M. Hidalgo and C. Lett for fruitful discussions, and J. Almany for proof-reading. The authors thank the editors (D. Currie, D. Tittensor) and the referees (J. Kool and an anonymous reviewer) whose comments helped improve this manuscript. 


\section{References}

Anadón, J.D., Mancha-Cisneros, M.d.M., Best, B.D., \& Gerber, L.R. 2013. Habitat-specific larval dispersal and marine connectivity: implications for spatial conservation planning. Ecosphere, 4(7), art82.

Andrello, M., Mouillot, D., Beuvier, J., Albouy, C., Thuiller, W., \& Manel, S. 2013. Low connectivity between Mediterranean marine protected areas: a biophysical modeling approach for the dusky grouper Epinephelus marginatus. PLoS ONE, 8(7), e68564.

Bakun, A., \& Agostini, V.N. 2001. Seasonal patterns of wind-induced upwelling/downwelling in the Mediterranean Sea. Scientia Marina, 65(3), 243-257.

Baums, I.B., Paris, C.B., \& Chérubin, L.M. 2006. A bio-oceanographic filter to larval dispersal in a reef-building coral. Limnology and Oceanography, 51(5), 1969-1981.

Bode, M., Bode, L., \& Armsworth, P.R. 2006. Larval dispersal reveals regional sources and sinks in Great Barrier Reef. Marine Ecology Progress Series, 308, 17-25.

Botsford, L.W., Brumbaugh, D.R., Grimes, C., Kellner, J.B., Largier, J., O’Farrell, M.R., Ralston, S., Soulanille, E., \& Wespestad, V. 2009. Connectivity, sustainability, and yield: bridging the gap between conventional fisheries management and marine protected areas. Reviews in Fish Biology and Fisheries, 19(1), 69-95.

Burgess, S.C., Nickols, K.J., Griesemer, C.D., Barnett, L.A.K., Dedrick, A.G., Satterthwaite, E.V., Yamane, L., Morgan, S.G., White, J.W., \& Botsford, L.W. 2014. Beyond connectivity: how empirical methods can quantify population persistence to improve marine protected-area design. Ecological Applications, 24(2), $257-270$.

Calò, A., Félix-Hackradt, F.C., Garcia, J., Hackradt, C.W., Rocklin, D., Treviño Otón, J., \& García-Charton, J.A. 2013. A review of methods to assess connectivity and dispersal between fish populations in the Mediterranean Sea. Advances in Oceanography and Limnology, 4(2), 150-175.

Carson, H.S., Cook, G.S., López-Duarte, P.C., \& Levin, L.A. 2011. Evaluating the importance of demographic connectivity in a marine metapopulation. Ecology, 92(10), 1972-1984.

Corell, H., Moksnes, P.O., Engqvist, A., Doos, K., \& Jonsson, P. 2012. Depth distribution of larvae critically affects their dispersal and the efficiency of marine protected areas. Marine Ecology Progress Series, 467, $29-46$.

Cowen, R.K., \& Sponaugle, S. 2009. Larval dispersal and marine population connectivity. Annual Review of Marine Science, 1, 443-466.

Cowen, R.K., Paris, C.B., \& Srinivasan, A. 2006. Scaling of connectivity in marine populations. Science, 311(5760), 522-527.

Crowder, L.B., Lyman, S.J., Figueira, W.F., \& Priddy, J. 2000. Source-sink population dynamics and the problem of siting marine reserves. Bulletin of Marine Science, 66(3), 799-820.

Foster, N.L., Paris, C.B., Kool, J.T., Baums, I.B., Stevens, J.R., Sanchez, J.A., Bastidas, C., Agudelo, C., Bush, P., Day, O., Ferrari, R., Gonzalez, P., Gore, S., Guppy, R., McCartney, M.A., McCoy, C., Mendes, J., Srinivasan, A., Steiner, S., Vermeij, M.J.A., Weil, E., \& Mumby, P.J. 2012. Connectivity of Caribbean coral populations: Complementary insights from empirical and modelled gene flow. Molecular Ecology, 21(5), $1143-1157$. 
Gaggiotti, O.E. 1996. Population Genetic Models of Source-Sink Metapopulations. Theoretical Population Biology, 50(2), $178-208$.

Gaines, S.D., Gaylord, B., Gerber, L.R., Hastings, A., \& Kinlan, B.P. 2007. Connecting places. Oceanography, $\mathbf{2 0}(3), 90$.

Guizien, K., Belharet, M., Marsaleix, P., \& Guarini, J.M. 2012. Using larval dispersal simulations for marine protected area design: Application to the Gulf of Lions (northwest Mediterranean). Limnology and Oceanography, 57(4), 1099.

Hastings, A., \& Botsford, L.W. 2006. Persistence of spatial populations depends on returning home. Proceedings of the National Academy of Sciences, 103(15), 6067-6072.

Hixon, M.A., Pacala, S.W., \& Sandin, S.A. 2002. Population regulation: historical context and contemporary challenges of open vs. closed systems. Ecology, 83(6), 1490-1508.

Hogan, J.D., Thiessen, R.J., Sale, P.F., \& Heath, D.D. 2012. Local retention, dispersal and fluctuating connectivity among populations of a coral reef fish. Oecologia, 168(1), 61-71.

Jolly, M.T., Guyard, P., Ellien, C., Gentil, F., Viard, F., Thiébaut, E., \& Jollivet, D. 2009. Population genetics and hydrodynamic modeling of larval dispersal dissociate contemporary patterns of connectivity from historical expansion into European shelf seas in the polychaete Pectinaria koreni. Limnology and Oceanography, 54(6), 2089.

Jones, G.P., Milicich, M.J., Emslie, M.J., \& Lunow, C. 1999. Self-recruitment in a coral reef fish population. Nature, 402(6763), 802-804.

Kinlan, B.P., \& Gaines, S.D. 2003. Propagule dispersal in marine and terrestrial environments: a community perspective. Ecology, 84(8), 2007-2020.

Kool, J.T., Paris, C.B., Barber, P.H., \& Cowen, R.K. 2011. Connectivity and the development of population genetic structure in Indo-West Pacific coral reef communities. Global Ecology and Biogeography, 20(5), 695-706.

Kool, J.T., Moilanen, A., \& Treml, E.A. 2013. Population connectivity: recent advances and new perspectives. Landscape Ecology, 28, 165-185.

Ledoux, J.B., Mokhtar-Jamaï, K., Roby, C., Féral, J.P, Garrabou, J., \& Aurelle, D. 2010. Genetic survey of shallow populations of the Mediterranean red coral [Corallium rubrum (Linnaeus, 1758)]: new insights into evolutionary processes shaping nuclear diversity and implications for conservation. Molecular Ecology, 19(4), 675-690.

Lenfant, P., \& Planes, S. 1996. Genetic differentiation of white sea bream within the Lion's Gulf and the Ligurian Sea (Mediterranean Sea). Journal of Fish Biology, 49(4), 613-621.

Lett, C., Nguyen-Huu, T., Cuif, M., Saenz-Agudelo, P., \& Kaplan, D.M. 2015. Linking local retention, selfrecruitment and persistence in marine metapopulations. Ecology, 96, 2236-2244.

Lowe, W.H., \& Allendorf, F.W. 2010. What can genetics tell us about population connectivity? Molecular Ecology, 19(15), 3038-3051.

Millot, C., \& Taupier-Letage, I. 2005. Circulation in the Mediterranean sea. Pages 29-66 of: The Mediterranean Sea. Springer. 
Mitarai, S., Siegel, D.A., Watson, J.R., Dong, C., \& McWilliams, J.C. 2009. Quantifying connectivity in the coastal ocean with application to the Southern California Bight. Journal of Geophysical Research - Oceans, 114(C10026).

Moffitt, E.A., Botsford, L.W., Kaplan, D.M., \& O'Farrell, M.R. 2009. Marine reserve networks for species that move within a home range. Ecological Applications, 19(7), 1835-1847.

Mokhtar-Jamaï, K., Pascual, M., Ledoux, J.B., Coma, R., Féral, J.P., Garrabou, J., \& Aurelle, D. 2011. From global to local genetic structuring in the red gorgonian Paramuricea clavata: the interplay between oceanographic conditions and limited larval dispersal. Molecular Ecology, 20(16), 3291-3305.

Mora, C., Treml, E.A., Roberts, J., Crosby, K., Roy, D., \& Tittensor, D.P. 2012. High connectivity among habitats precludes the relationship between dispersal and range size in tropical reef fishes. Ecography, 35(1), 89-96.

Nilsson-Jacobi, M., André, C., Doos, K., \& Jonsson, P.R. 2012. Identification of subpopulations from connectivity matrices. Ecography, 35, 1004-1016.

Oddo, P., Adani, M., Pinardi, N., Fratianni, C., Tonani, M., \& Pettenuzzo, D. 2009. A nested AtlanticMediterranean Sea general circulation model for operational forecasting. Ocean Science Discussions, 6(2), 1093-1127.

Palumbi, S.R. 2003. Population genetics, demographic connectivity, and the design of marine reserves. Ecological Applications, 13(sp1), 146-158.

Pannell, J.R., \& Charlesworth, B. 1999. Neutral genetic diversity in a metapopulation with recurrent local extinction and recolonization. Evolution, 664-676.

Paris, C.B., \& Cowen, R.K. 2004. Direct evidence of a biophysical retention mechanism for coral reef fish larvae. Limnology and Oceanography, 49(6), 1964-1979.

Pinardi, N., \& Masetti, E. 2000. Variability of the large scale general circulation of the Mediterranean Sea from observations and modelling: a review. Palaeogeography, Palaeoclimatology, Palaeoecology, 158(3), 153-173.

Pinsky, M.L., Palumbi, S.R., Andréfouët, S., \& Purkis, S.J. 2012. Open and closed seascapes: where does habitat patchiness create populations with high fractions of self-recruitment? Ecological Applications, 22(4), $1257-1267$.

Planes, S., Jones, G.P., \& Thorrold, S.R. 2009. Larval dispersal connects fish populations in a network of marine protected areas. Proceedings of the National Academy of Sciences, 106(14), 5693-5697.

Poulain, P.M., Menna, M., \& Mauri, E. 2012. Surface geostrophic circulation of the Mediterranean Sea derived from drifter and satellite altimeter data. Journal of Physical Oceanography, 42(6), 973-990.

Pulliam, H.R. 1988. Sources, sinks, and population regulation. American Naturalist, 652-661.

Reglero, P., Ciannelli, L., Alvarez-Berastegui, D., Balbín, R., López-Jurado, J.L., \& Alemany, F. 2012. Geographically and environmentally driven spawning distributions of tuna species in the western Mediterranean Sea. Marine Ecology Progress Series, 463, 273-284.

Riginos, C., Douglas, K.E., Jin, Y., Shanahan, D.F., \& Treml, E.A. 2011. Effects of geography and life history traits on genetic differentiation in benthic marine fishes. Ecography, 34(4), 566-575.

Roberts, C.M. 1997. Connectivity and management of Caribbean coral reefs. Science, 278(5342), 1454-1457. 
Rodriguez, J.M., Alvarez, I., Lopez-Jurado, J.L., Garcia, A., Balbin, R., Alvarez-Berastegui, D., Torres, A.P., \& Alemany, F. 2013. Environmental forcing and the larval fish community associated to the Atlantic bluefin tuna spawning habitat of the Balearic region (Western Mediterranean), in early summer 2005. Deep-Sea Research Part I, 77, 11-22.

Rossi, V., Ser-Giacomi, E., López, C., \& Hernández-García, E. 2014. Hydrodynamic provinces and oceanic connectivity from a transport network help designing marine reserves. Geophysical Research Letters, $4 \mathbf{1 1}(8)$, $2883-2891$.

Saenz-Agudelo, P., Jones, G.P., Thorrold, S.R., \& Planes, S. 2011. Connectivity dominates larval replenishment in a coastal reef fish metapopulation. Proceedings of the Royal Society B: Biological Sciences.

Schunter, C., Carreras-Carbonell, J., Macpherson, E., Tintoré, J., Vidal-Vijande, E., Pascual, A., Guidetti, P., \& Pascual, M. 2011. Matching genetics with oceanography: directional gene flow in a Mediterranean fish species. Molecular Ecology, 20(24), 5167-5181.

Ser-Giacomi, E., Rossi, V., Lopez, C., \& Hernandez-Garcia, E. 2015. Flow networks: A characterization of geophysical fluid transport. Chaos, 25, 036404.

Shanks, A.L., Grantham, B.A., \& Carr, M.H. 2003. Propagule dispersal distance and the size and spacing of marine reserves. Ecological Applications, 13(1), 159-169.

Siegel, D.A., Mitarai, S., Costello, C.J., Gaines, S.D., Kendall, B.E., Warner, R.R., \& Winters, K.B. 2008. The stochastic nature of larval connectivity among nearshore marine populations. Proceedings of the National Academy of Sciences, 105(26), 8974-8979.

Soria, G., Munguía-Vega, A., Marinone, S.G., Moreno-Báez, M., Martínez-Tovar, I., \& Cudney-Bueno, R. 2012. Linking bio-oceanography and population genetics to assess larval connectivity. Marine Ecology Progress Series, 463, 159-175.

Thomas, L., \& Bell, J.J. 2013. Testing the consistency of connectivity patterns for a widely dispersing marine species. Heredity, 111, 345-354.

Treml, E.A., Roberts, J.J., Chao, Y., Halpin, P.N., Possingham, H.P., \& Riginos, C. 2012. Reproductive output and duration of the pelagic larval stage determine seascape-wide connectivity of marine populations. Integrative and Comparative Biology, 52(4), 525-537.

Weersing, K., \& Toonen, R.J. 2009. Population genetics, larval dispersal, and connectivity in marine systems. Marine Ecology Progress Series, 393(1), 12.

White, C., Selkoe, K.A., Watson, J., Siegel, D. A, Zacherl, D.C., \& Toonen, R.J. 2010. Ocean currents help explain population genetic structure. Proceedings of the Royal Society B: Biological Sciences.

Wood, S., Paris, C.B., Ridgwell, A., \& Hendy, E.J. 2014. Modelling dispersal and connectivity of broadcast spawning corals at the global scale. Global Ecology and Biogeography, 23(1), 1-11.

Young, C.M., He, R., Emlet, R.B., Li, Y., Qian, H., Arellano, S.M., Van Gaest, A., Bennett, K.C., Wolf, M., Smart, T.I., \& Rice, M.E. 2012. Dispersal of deep-sea larvae from the intra-American seas: Simulations of trajectories using ocean models. Integrative and Comparative Biology, 52(4), 483-496. 


\section{Biosketch}

Mélodie Dubois was a master student at IFISC and is now enrolled in a PhD at CRIOBE. Her research focuses on modelling ecological and social dynamics to improve fisheries management. Dr. Vincent Rossi (http://ifisc.uib-csic.es/users/vincent/) is a post-doctoral researcher at IFISC. He is interested in multidisciplinary and contemporary issues encompassing Physical \& Biological Oceanography and Marine Ecology. Enrico Ser-Giacomi has just completed his PhD that takes Dynamical Systems and Complex Networks perspectives to investigate geophysical flows. This research team composed of physicists (E.S.-G., C.L. and E.H.-G.), oceanographer (V.R.), marine ecologist (M.D.) and evolutionary ecologist (S.A.-H.) aims to study the spatial structure and dynamics of marine populations from ecosystemic and multidisciplinary approaches to propose globally pertinent conservation plans and management strategies. 


\section{Appendix 1: Data sources}

Bauchot, M.L., \& Hureau, J.C. 1990. Sparidae. Pages 790-812 of: Quero, J.C., Hureau, J.C., Karrer, C., A., Post, \& Saldanha, L. (eds), Check-list of the fishes of the eastern tropical Atlantic, vol. 2. JNICT, Lisbon and SEI/UNESCO, Paris.

Bauchot, M.L., \& Quignard, J.P. 1979. Labridae. Pages 426-443 of: Hureau, J.C., \& Monod, T. (eds), Check-list of the fishes of the north-eastern Atlantic and of the Mediterranean, vol. 1. UNESCO, Paris.

Coll, M., Cury, P., Azzurro, E., Bariche, M., Bayadas, G., Bellido, J.M., Chaboud, C., Claudet, J., El-Sayed, A.F., Gascuel, D., et al. 2013. The scientific strategy needed to promote a regional ecosystem-based approach to fisheries in the Mediterranean and Black Seas. Reviews in Fish Biology and Fisheries, 23(4), 415-434.

d’Ovidio, F., Fernández, V., Hernández-García, E., \& López, C. 2004. Mixing structures in the Mediterranean Sea from finite-size Lyapunov exponents. Geophysical Research Letters, 31(17).

Dulčić, J. 1999. First record of larval Brama brama (Pisces: Bramidae) and Coryphaena hippurus (Pisces: Coryphaenidae) in the Adriatic sea. Journal of Plankton Research, 6, 1171-1174.

Fratini, S., Ragionieri, L., Cutuli, G., Vannini, M., \& Cannicci, S. 2013. Pattern of genetic isolation in the crab Pachygrapsus marmoratus within the Tuscan Archipelago (Mediterranean Sea). Marine Ecology Progress Series, 478, 173-183.

Guidetti, P., Notarbartolo-Di-Sciara, G., \& Agardy, T. 2013. Integrating pelagic and coastal MPAs into large-scale ecosystem-wide management. Aquatic Conservation: Marine and Freshwater Ecosystems, 23(1), 179-182.

Houde, E.D., \& Zastrow, C.E. 1993. Ecosystem-and taxon-specific dynamic and energetics properties of larval fish assemblages. Bulletin of Marine Science, 53(2), 290-335.

Kough, A.S., Paris, C.B., \& Butler, M.J. 2013. Larval Connectivity and the International Management of Fisheries. PLoS ONE, 8(6), e64970.

MacPherson, E., \& Raventós, N. 2006. Relationship between pelagic larval duration and geographic distribution in Mediterranean littoral fishes. Marine Ecology Progress Series, 327, 257-265.

Morales-Nin, B., \& Moranta, J. 2004. Recruitment and post-settlement growth of juvenile Merluccius merluccius on the western Mediterranean shelf. Scientia Marina, 68(3), 399-409.

Pikitch, E., Santora, E.A., Babcock, A., Bakun, A., Bonfil, R., Conover, D.O., Dayton, P., Doukakis, P., Fluharty, D., Heheman, B., Houde, E.D., Link, J., Livingston, P.A., Mangel, M., McAllister, M.K., Pope, J., \& K.J., Sainsbury. 2004. Ecosystem-based fishery management. Science, 305, 346-347.

Queiroga, H., Dos-Santos, A., Dubert, J., Gonzalez-Gordillo, I., Paula, J., Peliz, A., \& Santos, A.M.P. 2007. Oceanographic and behavioural processes affecting invertebrate larval dispersal and supply in the western Iberia upwelling ecosystem. Progress in Oceanography, $\mathbf{7 4}, 174-$ 191.

Ramirez, T., Cortés, D., \& Garcia, A. 2001. Growth of North Alboran Sea sardine larvae estimated by otolith microstructure, nucleic acids and protein content. Journal of Fish Biology, 59, 403-415.

Raventós, N., \& MacPherson, E. 2001. Planktonic larval duration and settlement marks on the otoliths of Mediterranean littoral fishes. Marine Biology, 138, 1115-1120.

Rooker, J.R., Alvarado Bremer, J.R., Block, B.A., Dewar, H., De Metrio, G., Corriero, A., Kraus, R.T., Prince, E.D., Rodríguez-Marín, E., \& Secor, D.H. 2007. Life history and stock structure of Atlantic bluefin tuna (Thunnus thynnus). Reviews in Fisheries Science, 15(4), $265-310$.

Sabatés, A., Zabala, M., \& García-Rubies, A. 2003. Larval fish communities in the Medes Islands Marine Reserve (north-west Mediterranean). Journal of Plankton Research, 25(9), 1035-1046.

Shanks, A.L. 2009. Pelagic larval duration and dispersal distance revisited. The Biological Bulletin, 216(3), 373-385.

Smith, C.L. 1990. Moronidae. Pages 692-694 of: Quero, J.C., Hureau, J.C., Karrer, C., A., Post, \& Saldanha, L. (eds), Check-list of the fishes of the eastern tropical Atlantic, vol. 2. JNICT, Lisbon and SEI/UNESCO, Paris.

Smith-Vaniz, W.F. 1986. Carangidae. Pages 815-844 of: Whitehead, P.J.P., Bauchot, M.L., Hureau, J.C., Nielsen, J., \& Tortonese, E. (eds), Fishes of the north-eastern Atlantic and the Mediterranean, vol. 2. UNESCO, Paris.

Torres, A.P., Reglero, P., Balbin, R., Urtizberea, A., \& Alemany, F. 2011. Coexistence of larvae of tuna species and other fish in the surface mixed layer in the NW Mediterranean. Journal of Plankton Research, 33(12), 1793-1812.

Zulliger, D.E., Tanner, S., Ruch, M., \& Ribi, G. 2009. Genetic structure of the high dispersal Atlanto-Mediterreanean sea star Astropecten aranciacus revealed by mitochondrial DNA sequences and microsatellite loci. Marine Biology, 156, 597-610. 


\section{Linking basin-scale connectivity, oceanography and population}

dynamics for the conservation and management of marine ecosystems. SUPPORTING INFORMATION

Mélodie Dubois ${ }^{1,3}$, Vincent Rossi ${ }^{1^{*}}$, Enrico Ser-Giacomi ${ }^{1}$, Sophie Arnaud-Haond ${ }^{2}$, Cristóbal López ${ }^{1}$, and Emilio Hernández-García ${ }^{1}$

${ }^{1}$ IFISC (Institute for Cross-Disciplinary Physics and Complex Systems), CSIC-UIB, Palma de Mallorca 07122, Spain.

${ }^{2}$ IFREMER, Unité Halieutique Méditerranée du Département Ressources Biologiques et Environnement - UMR212 - Ecosystèmes Marins Exploités, Sète, France.

${ }^{3}$ Presently at: CRIOBE, USR 3278, EPHE-CNRS-UPVD, 58 Av. Paul Alduy, 66860

Perpignan Cedex, France.

January 18, 2016

[*]Corresponding author (vincent@ifisc.uib-csic.es; vincent.rossi.ocean@gmail.com / tel: +34 971259830 ). 


\section{Appendix 2: Connectivity proxies distribution and sensitivity analy-} sis

To explore the variability of the connectivity metrics and their sensitivity to the most relevant parameters, we study their mapping and their probability distribution function with the Complementary Cumulative Distribution Function $(\mathrm{CCDF})$ given by $F(x)=$ Prob. $(X>x)$. In other words, $F(x) \in[0,1]$ represents the proportion of values $X$ that are strictly higher than the threshold $x$. The CCDFs of strengths, degrees and SourceSink are computed using a binning with regular intervals of 0.002 (corresponding to the numerical resolution of the model 1/500), 1 and 0.005 , respectively.

We also investigate the sensitivity of the CCDFs for each connectivity metric depending on the parameters $\tau=P L D$ and $t_{0}=$ spawning period considered independently. For instance, to highlight the effect of the $P L D$ on the distribution of $P_{i, j}$ and $L_{i, j}$, we build a single CCDF taking into account all 60 simulations that used the same integration time $\tau=P L D=30$ days and we compare it to the CCDF build with the other 60 simulations using $\tau=P L D=60$ days. Similarly, we test the seasonal effect alone, the inter-annual variability alone, and finally the full variability considering all effects together on every connectivity proxy.

\subsection{Statistical distributions}

Our two retention metrics (LR and SR) show very similar density functions. On average over all simulations (Fig. SI-1 $)$, more than $50 \%$ of boxes have null LR and SR, indicating they never retain particle in their core at the end of the simulations. High values of LR and SR ( $>50 \%)$ are rarely found in less than $3 \%$ of oceanic boxes (which corresponds approximatively to 95 nodes with our discretization). Considering the SourceSink metrics, the CCDFs indicate that about $30 \%$ of all sites tend to behave as larval sink ( $\geq 0.6)$ and $30 \%$ as larval source $(\leq 0.4)$ in terms of degree $\left(S S^{d}\right)$. In terms of strength $\left(S S^{s}\right)$, less than $20 \%$ of all nodes appear as sink and $35 \%$ are sources (Fig. SI-1b and c).

\subsection{Sensitivity to the Pelagic Larval Duration}

For most proxies, the Pelagic Larval Duration (PLD) is the most important factor of variability as it has the largest impact on the shape of the CCDF curves. The longer the PLD, the larger larval dispersion and the smaller retention rates. This is evidenced by the smaller absolute values of SR and LR for PLDs of 60 days as compared to 30 days (Fig. SI-1 d). Stronger dispersion is evidenced by a greater number of links (Fig. SI-1p), a larger spread of their distribution and by higher export rates for longer PLDs (not shown). The effect of the PLD on the source/sink dynamics is more complex. The distributions of both $S S$ metrics suggest that longer PLDs are associated with slightly higher proportions of source versus sink regions (Fig. SI-1f), especially for the strength analyses. For instance, about $35 \%$ of boxes have $S S^{s} \leq 0.4$ (source) with a PLD of 60 days but less than $25 \%$ of boxes are source with a PLD of 30 days. These results confirm the fact that PLD of marine organisms is a good predictor of their larval dispersal potential Shanks et al. 2003]. We also find that the strong dispersal potential for long PLD is evident with stronger larval fluxes (strength) and dispersive pathways with more diverse destinations and origins (degrees). Finally, while the impact of PLD on source/sink dynamics has apparently not been studied previously, our results suggest that organisms with longer PLDs would tend to be more characterized as larval sources than as sinks.

\subsection{Sensitivity to the spawning time}

For each proxy, the variability due to the season of spawning $\left(t_{0} \in\right.$ January or $t_{0} \in$ July) is similar in magnitude to the inter-annual variability $\left(t_{0} \in 2002-2011\right)$ (Fig. SI-1 $, \mathrm{h}, \mathrm{i}$ and $\mathrm{j}, \mathrm{k}, \mathrm{l}$ ). Apart from SR and LR, winter simulations tend to enhance the spread of the CCDFs with higher frequencies in high values. More specifically, 

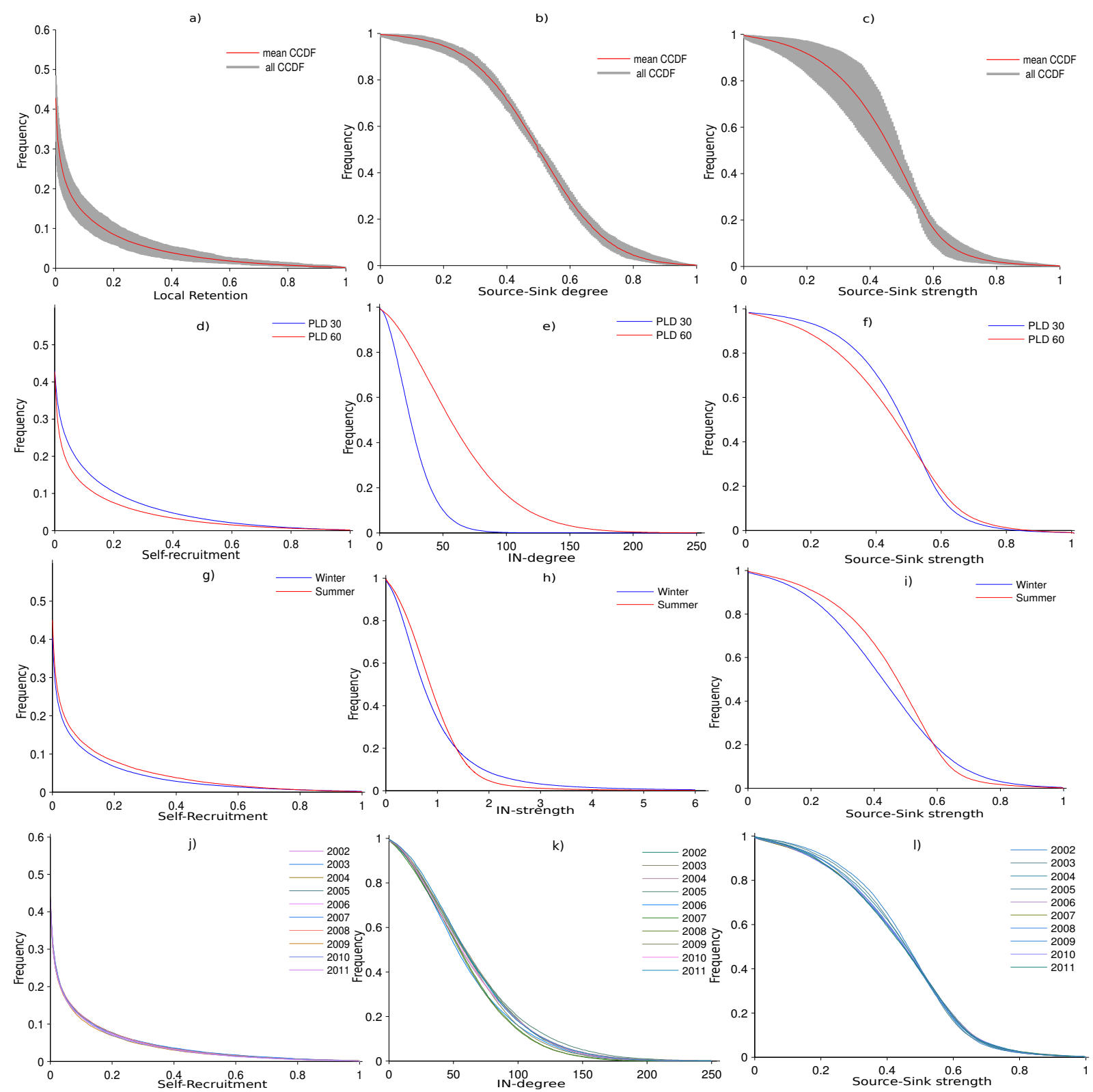

Figure SI-1: First row: mean Complementary Cumulative Distribution Function (CCDF) (red line) and its variability considering all experiments separately (grey shading) for (a) LR , (b) SourceSink-degree $\left(S S^{d}\right)$ and (c) SourceSink-strength $\left(S S^{s}\right)$. Second row: Effect of the PLD on CCDFs of (d) SR, (e) IN - degree and (f) $S S^{s}$. Third row: Effect of the season of spawning $\left(t_{0}\right)$, considering a fixed PLD of 30 days, on CCDFs of $(\mathrm{g})$ SR, (h) $I N-$ strength and (i) $S S^{s}$. Fourth row: Effect of the year of spawning $\left(t_{0}\right)$, considering a fixed PLD of 30 days, on CCDFs of (j) SR, (k) $I N$ - degree and (l) $S S^{s}(\mathrm{l})$. 
42 it leads to stronger export during winter evidenced by lower retention (Fig. SI-1s) and of $I N^{s}>1$ (Fig. SI-

${ }_{43}$ 17). This is also observed on the degree analyses with higher occurrence of large degrees (not shown). This

${ }_{44}$ is probably related to the enhanced winter mixing in the surface ocean d'Ovidio et al. 2004] which leads to

45 stronger and more anisotropic larval dispersal in the surface ocean. As a consequence, slightly smaller LR and

46 SR are generally observed in winter times (Figure SI-1 $\mathrm{s}$ ). The seasonal variability of both $S S$ metrics is more

${ }_{47}$ puzzling. In terms of degree, winter simulations show a small increase of the proportions of sink boxes (not

48 shown), whereas $S S$-strength distributions reveal that source boxes are more frequent in winter than in summer

49 (Fig. SI-1). 


\subsection{Sensitivity to the spatial discretization}

a)

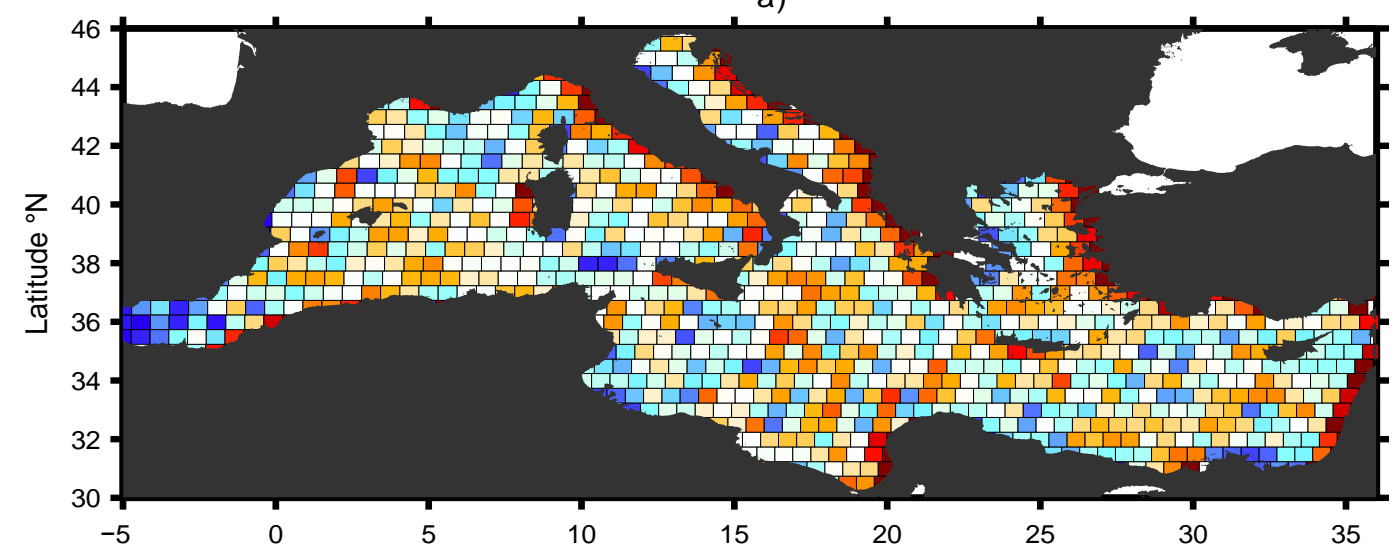

b)

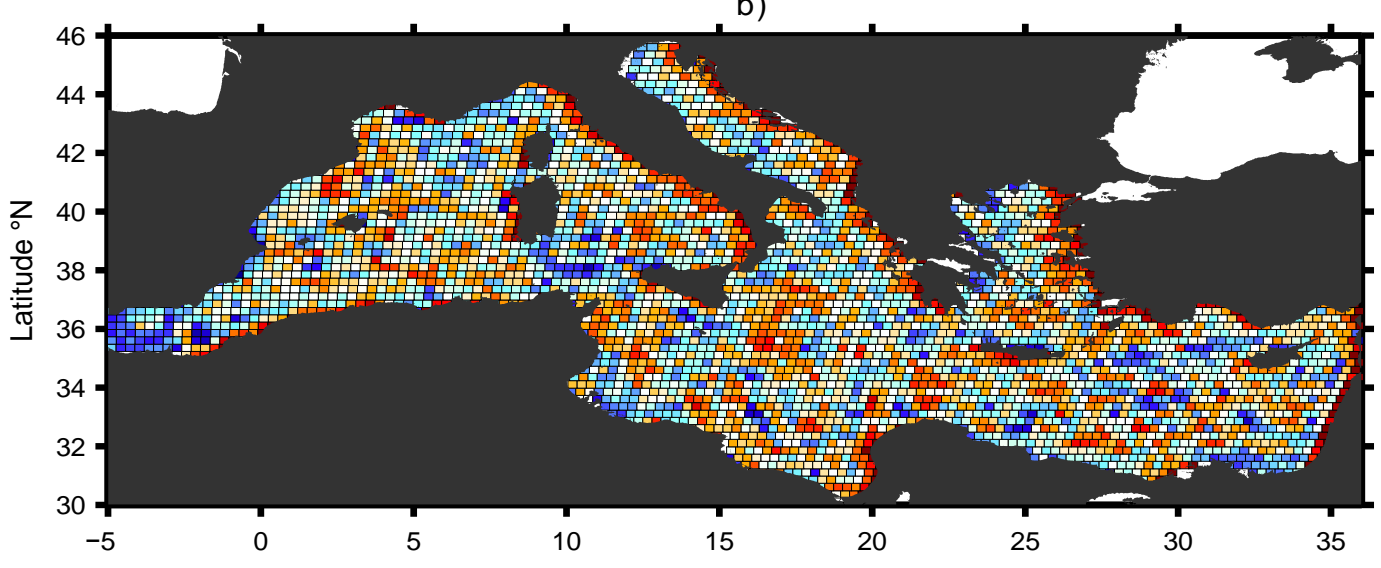

c)

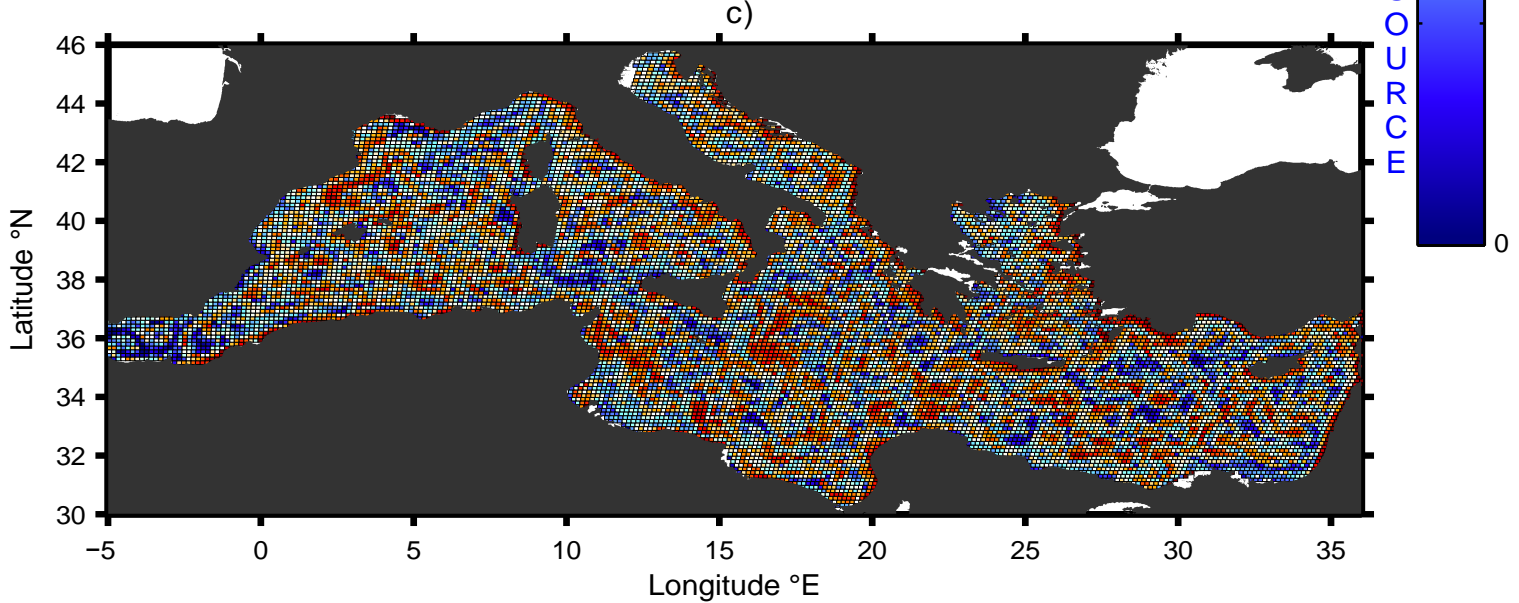

Figure SI-2: Snapshot maps of the SourceSink-degree $\left(S S^{d}\right)$ generated with same parameters but for network grids of (a) low $\left(1 / 2^{\circ}\right)$, (b) medium $\left(1 / 4^{\circ}\right.$, i.e. the resolution used in the manuscript) and (c) high resolution $\left(1 / 8^{\circ}\right)$. Note the very good agreement in the large-scale connectivity patterns among these snapshots, indicating no significant sensitivity of the averages depicted in the manuscript. 


\subsection{Sensitivity to initial density of particles}

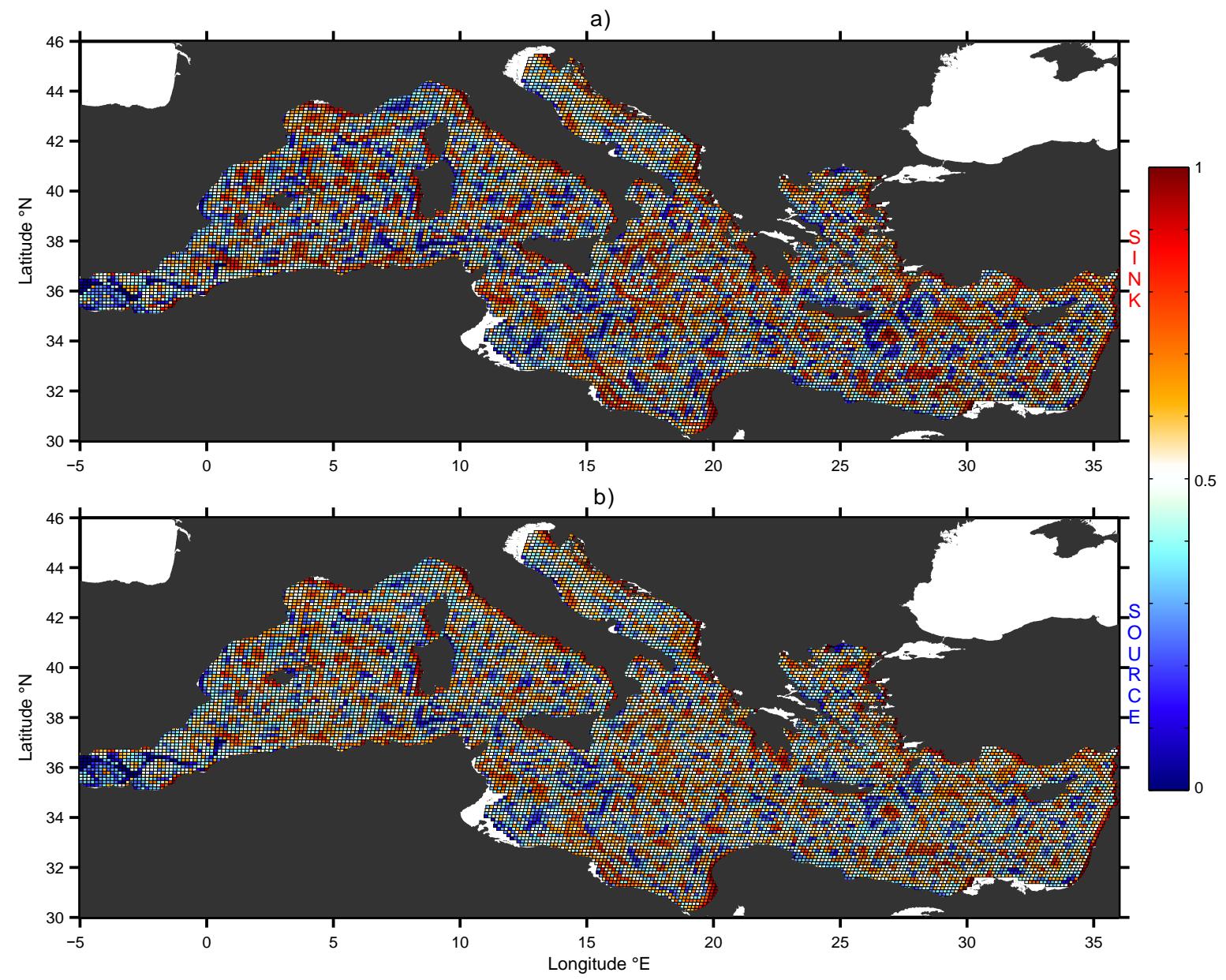

Figure SI-3: Snapshot maps of Source-Sink degree $\left(S S^{d}\right)$ generated with same parameters but for different latitudinal spacing (the distance between two tracers in the initial grid) (a) of $0.0042^{\circ}$ (corresponding to approximatively 1000 particles per node of $1 / 8^{\circ}$ ), and (b) of $0.0125^{\circ}$ (corresponding to about 100 particles per node of $\left.1 / 8^{\circ}\right)$. The spatial patterns and their magnitudes are very similar among those plots, suggesting no significant sensitivity of the averages described in the manuscript. 


\section{${ }_{52}$ Appendix 3: Additional figures and table}

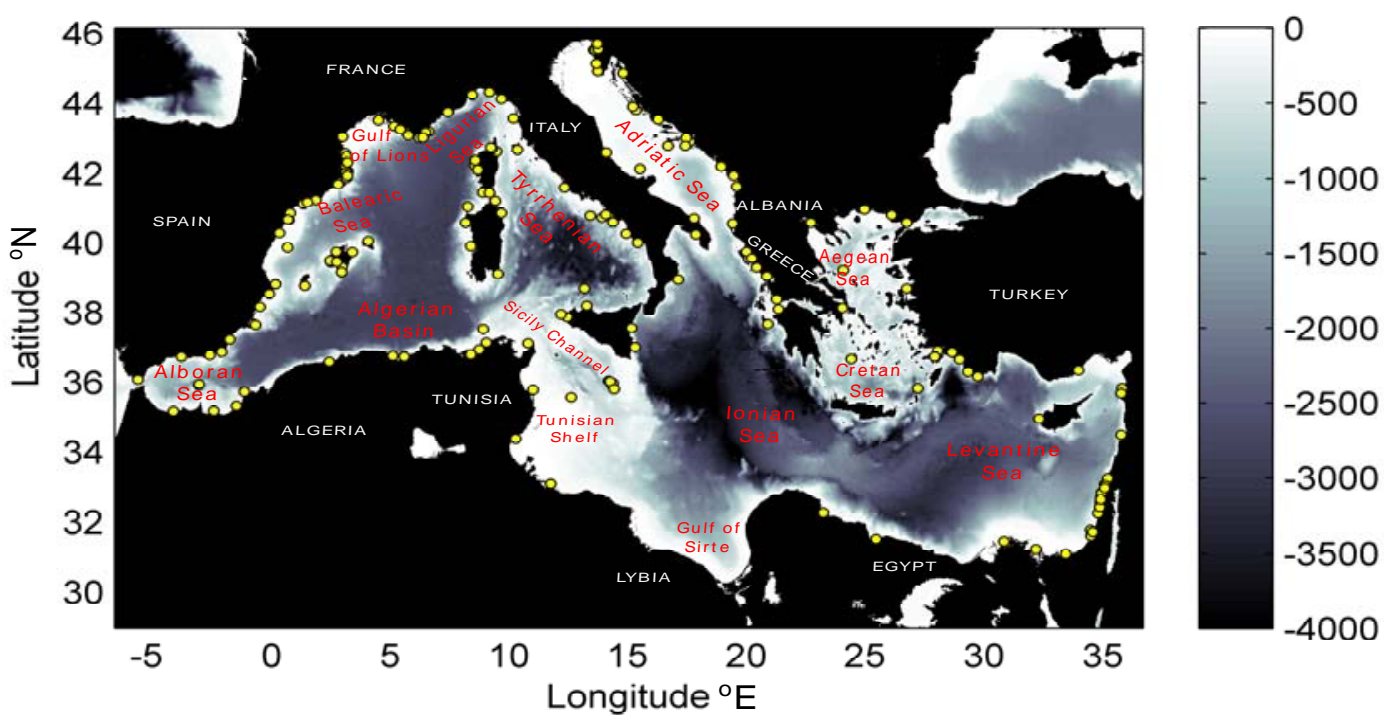

Figure SI-4: Overall geography and bathymetry (GEBCO) of the Mediterranean basin. Yellow dots represent the current network of Marine Protected Areas (MPAs coordinates were downloaded from the MedPan database). 


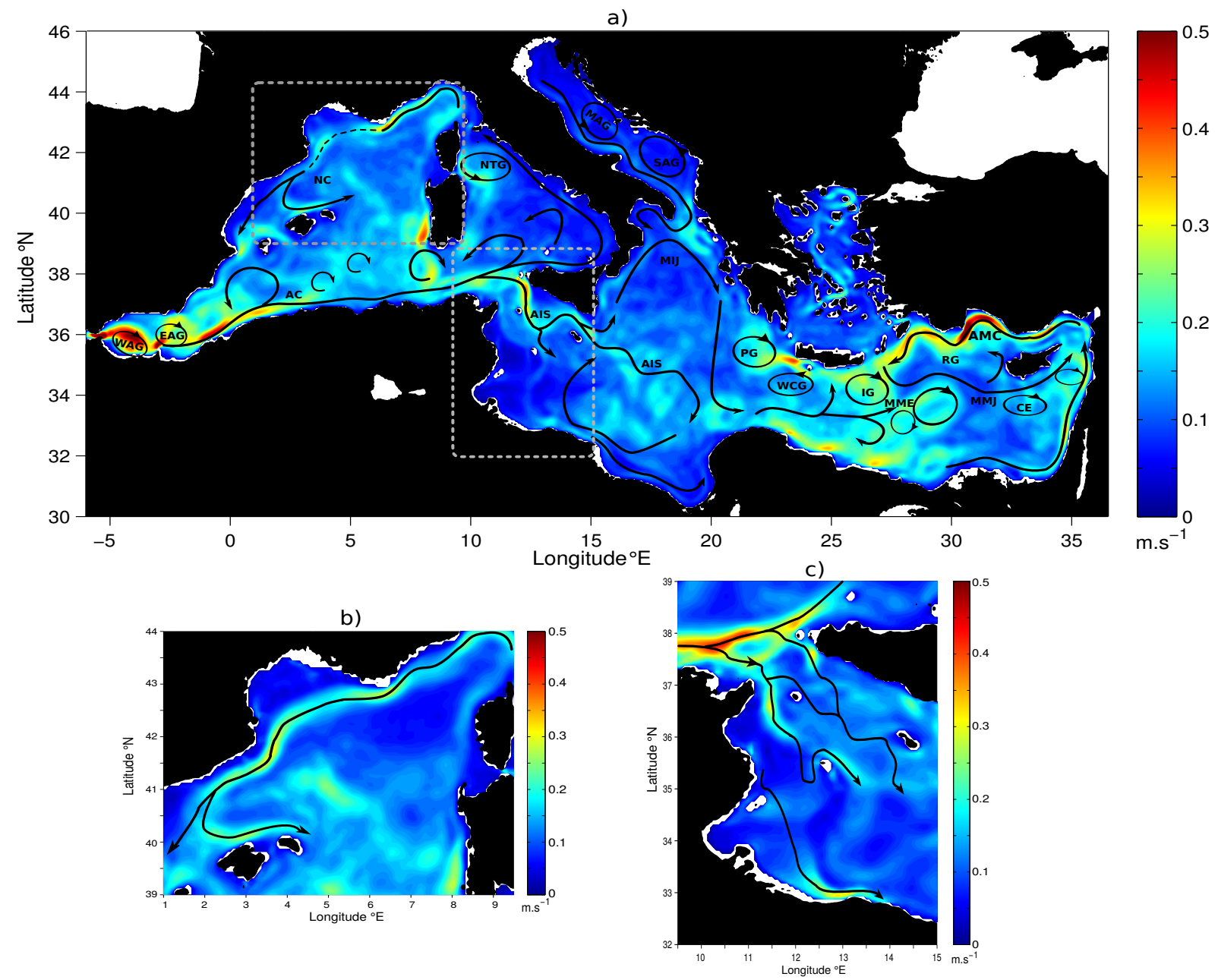

Figure SI-5: Schematic representation of surface currents adapted from Poulain et al. 2012], superimposed on the mean modulus $\left(m . s^{-1}\right)$ of the surface velocity field produced by MyOcean hydrodynamical model averaged over 2002 - 2011 a) considering all summer months (July/August) and b) regional zooms (as indicated by the grey rectangles on the upper panel) using all winter months (January/February). AC = Algerian Current, AIS = Atlantic-Ionian Stream, AMC $=$ Asian Minor Current, CE $=$ Cyprus Eddy, EAG $/$ WAG $=$ Eastern/Western Alboran Gyre, IG = Iearapetra Gyre, MIJ = Mid-Ionian Jet, MME = Mersa-Matruh Eddy, MMJ = Mid-Mediterranean Jet, NC = Northern Current, PG = Pelops Gyre, RG = Rhodes Gyre, SAG/MAG $=$ Southern/Middle Adriatic Gyre. 


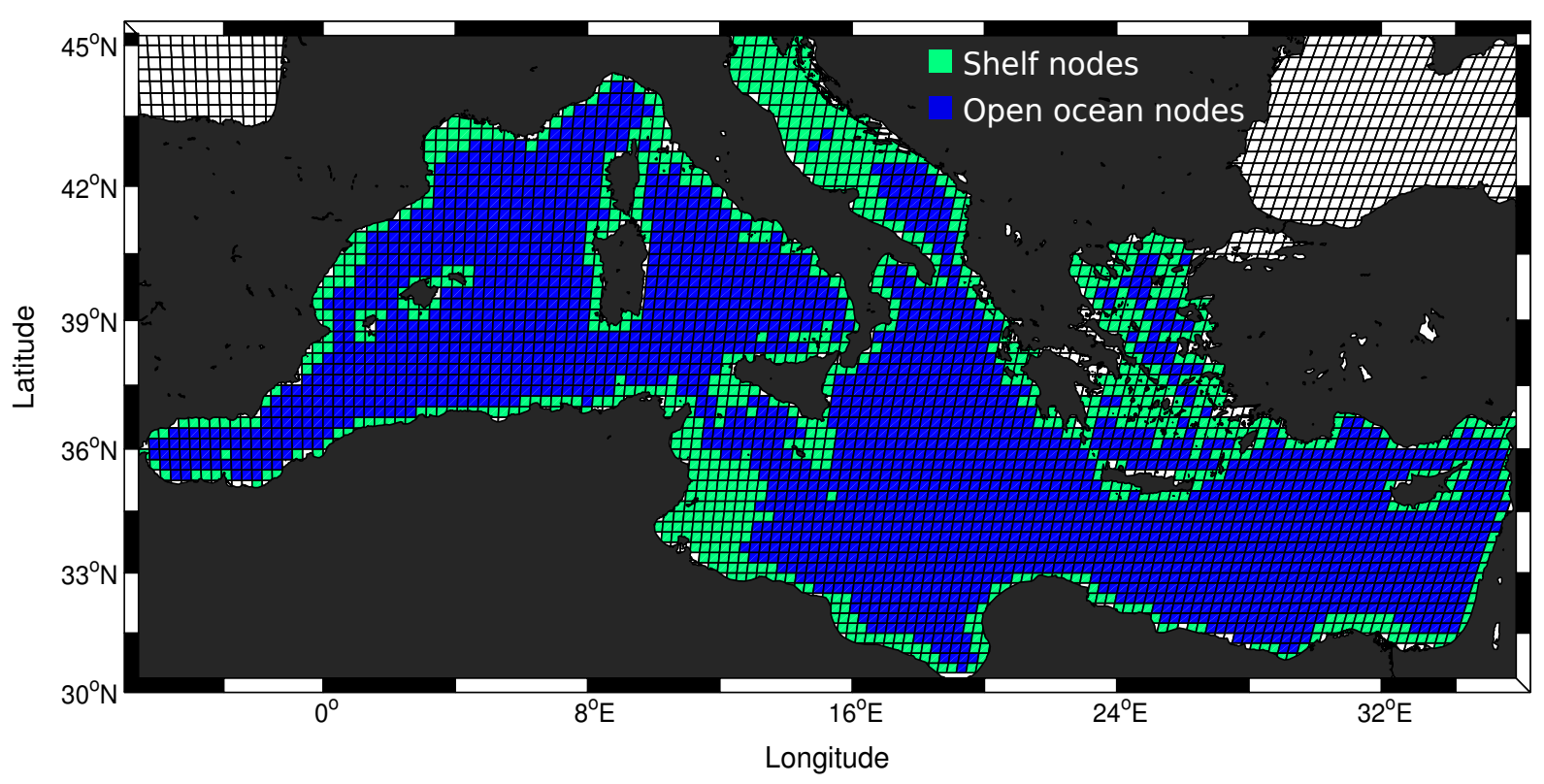

Figure SI-6: By co-locating the geographical coordinates of each node with a gridded bathymetry (GEBCO), one can distinguish the shelf and oceanic nodes (according to the color code). Following similar methodology, further ecologically-relevant distinction could be made in the future, such as separating the four main bathymetric floors (infra-, circa-littoral, bathyal and abyssal) or using the proportion of a specific benthic habitat in each node (see also Discussion sect. 4.4). 

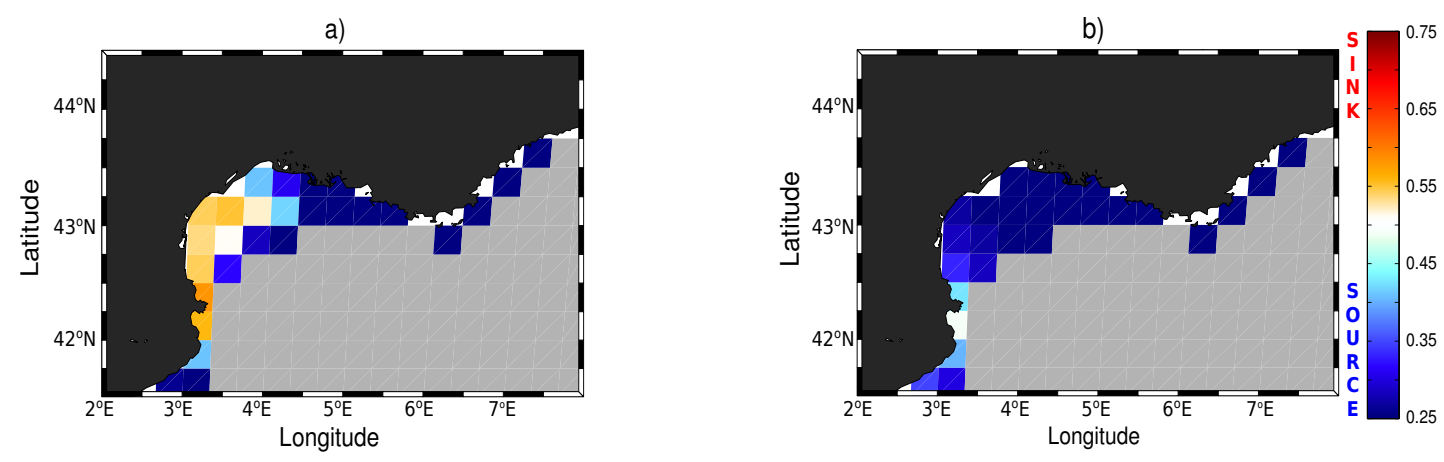

c)
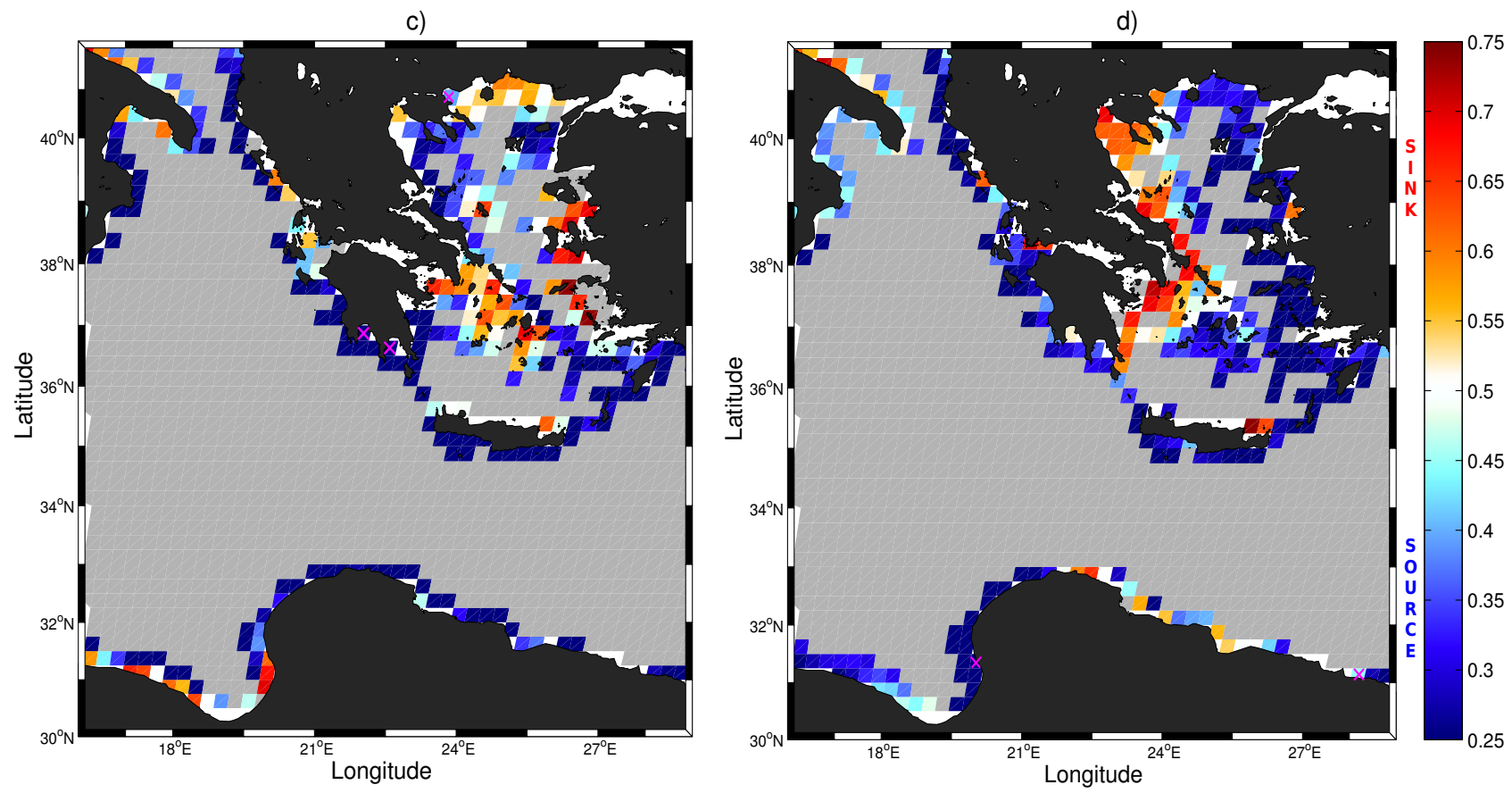

Figure SI-7: Regional zooms of the mean Source Sink-degree averaged over 30 winter (a, c) and 30 summer (b, d) connectivity matrices for a PLD of 60 days. Zooms on the Gulf of Lion (a,b) and Ionian and Aegean (c,d) regions. Grey areas represent the oceanic nodes that were disregarded from these analyses. 


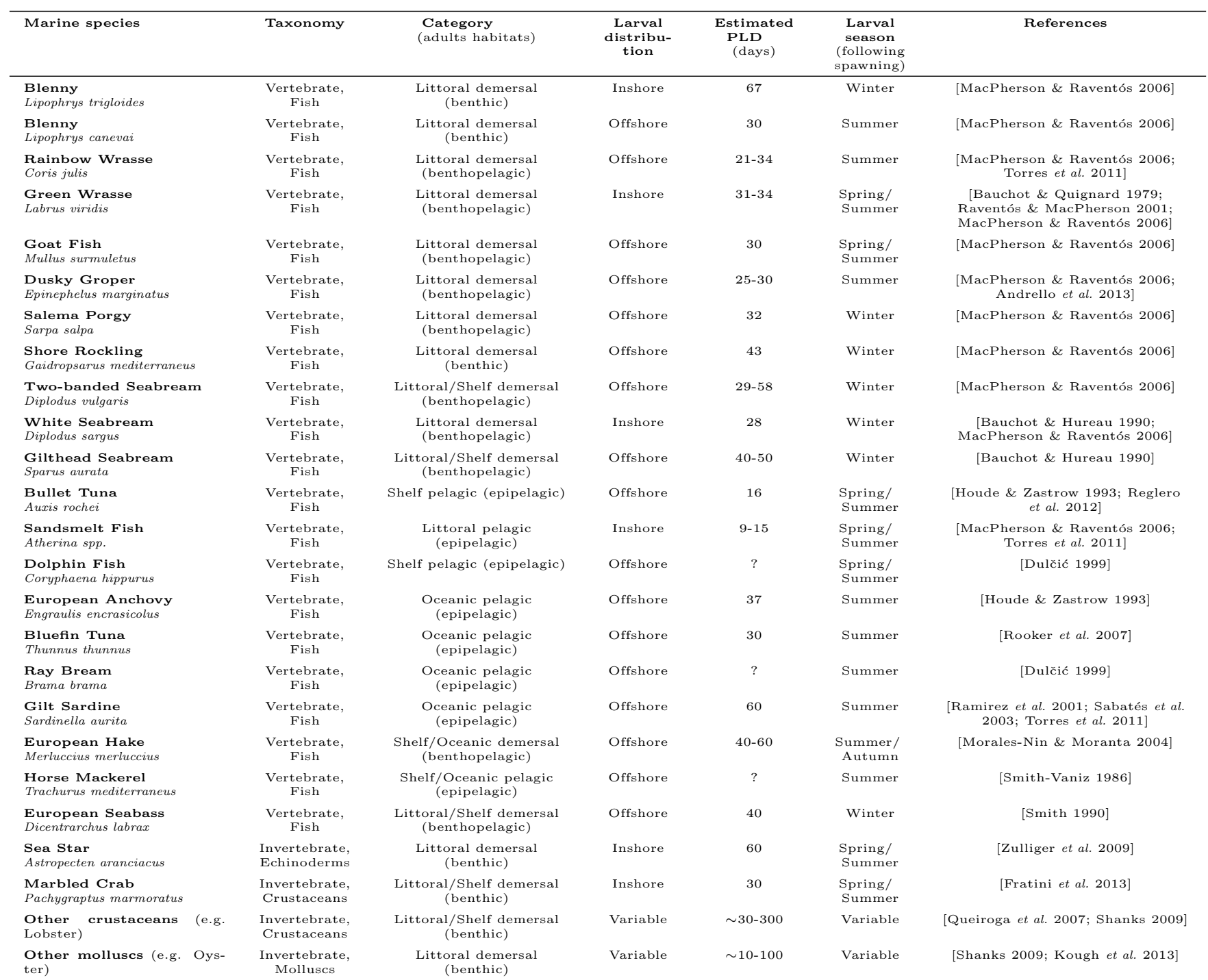

Table SI-1: Literature review of biological traits for some emblematic Mediterranean marine species with wide geographical range and potential for large-scale dispersal. With our parameter values and under our assumptions, the broad-scale connectivity patterns evidenced in this paper are applicable for those organisms that belong to different trophic levels of the Mediterranean food webs. Note that the vertical positioning of eggs/larvae may vary but for simplicity, they are assumed here to remain in the $\sim 50-150 \mathrm{~m}$ thick Mixed Layer Depth, thus seeing relatively similar transport patterns (see also Discussion sect. 4.4). While we take here an "ecosystem approach" to study connectivity, following what has been recommended for the management of marine resources [e.g. Pikitch et al. 2004, Coll et al. 2013 Guidetti et al.|2013], one could obtain refined predictions by tuning our modelling framework to any target specie with well-known biological traits and to any oceanic area. Category: Littoral $\sim 0-50 \mathrm{~m}$; Shelf $\sim 50-200 \mathrm{~m}$; Oceanic $\geq 200 \mathrm{~m}$. Larval distribution: Inshore $\sim 0-50 \mathrm{~m}$; Offshore $\geq 50 \mathrm{~m}$ (shelf and oceanic waters). 


\section{${ }_{53}$ References}

Andrello, M., Mouillot, D., Beuvier, J., Albouy, C., Thuiller, W., \& Manel, S. 2013. Low connectivity between Mediterranean marine protected areas: a biophysical modeling approach for the dusky grouper Epinephelus marginatus. PLoS ONE, 8(7), e68564.

Bauchot, M.L., \& Hureau, J.C. 1990. Sparidae. Pages 790-812 of: Quero, J.C., Hureau, J.C., Karrer, C., A., Post, \& Saldanha, L. (eds), Check-list of the fishes of the eastern tropical Atlantic, vol. 2. JNICT, Lisbon and SEI/UNESCO, Paris.

Bauchot, M.L., \& Quignard, J.P. 1979. Labridae. Pages 426-443 of: Hureau, J.C., \& Monod, T. (eds), Check-list of the fishes of the north-eastern Atlantic and of the Mediterranean, vol. 1. UNESCO, Paris.

Coll, M., Cury, P., Azzurro, E., Bariche, M., Bayadas, G., Bellido, J.M., Chaboud, C., Claudet, J., El-Sayed, A.F., Gascuel, D., et al. 2013. The scientific strategy needed to promote a regional ecosystem-based approach to fisheries in the Mediterranean and Black Seas. Reviews in Fish Biology and Fisheries, 23(4), 415-434.

d’Ovidio, F., Fernández, V., Hernández-García, E., \& López, C. 2004. Mixing structures in the Mediterranean Sea from finite-size Lyapunov exponents. Geophysical Research Letters, 31(17).

Dulčić, J. 1999. First record of larval Brama brama (Pisces: Bramidae) and Coryphaena hippurus (Pisces: Coryphaenidae) in the Adriatic sea. Journal of Plankton Research, 6, 1171-1174.

Fratini, S., Ragionieri, L., Cutuli, G., Vannini, M., \& Cannicci, S. 2013. Pattern of genetic isolation in the crab Pachygrapsus marmoratus within the Tuscan Archipelago (Mediterranean Sea). Marine Ecology Progress Series, 478, 173-183.

Guidetti, P., Notarbartolo-Di-Sciara, G., \& Agardy, T. 2013. Integrating pelagic and coastal MPAs into largescale ecosystem-wide management. Aquatic Conservation: Marine and Freshwater Ecosystems, 23(1), 179182.

Houde, E.D., \& Zastrow, C.E. 1993. Ecosystem-and taxon-specific dynamic and energetics properties of larval fish assemblages. Bulletin of Marine Science, 53(2), 290-335.

Kough, A.S., Paris, C.B., \& Butler, M.J. 2013. Larval Connectivity and the International Management of Fisheries. PLoS ONE, 8(6), e64970.

MacPherson, E., \& Raventós, N. 2006. Relationship between pelagic larval duration and geographic distribution in Mediterranean littoral fishes. Marine Ecology Progress Series, 327, 257-265.

Morales-Nin, B., \& Moranta, J. 2004. Recruitment and post-settlement growth of juvenile Merluccius merluccius on the western Mediterranean shelf. Scientia Marina, 68(3), 399-409.

Pikitch, E., Santora, E.A., Babcock, A., Bakun, A., Bonfil, R., Conover, D.O., Dayton, P., Doukakis, P., Fluharty, D., Heheman, B., Houde, E.D., Link, J., Livingston, P.A., Mangel, M., McAllister, M.K., Pope, J., \& K.J., Sainsbury. 2004. Ecosystem-based fishery management. Science, 305, 346-347.

Poulain, P.M., Menna, M., \& Mauri, E. 2012. Surface geostrophic circulation of the Mediterranean Sea derived from drifter and satellite altimeter data. Journal of Physical Oceanography, 42(6), 973-990.

Queiroga, H., Dos-Santos, A., Dubert, J., Gonzalez-Gordillo, I., Paula, J., Peliz, A., \& Santos, A.M.P. 2007. Oceanographic and behavioural processes affecting invertebrate larval dispersal and supply in the western Iberia upwelling ecosystem. Progress in Oceanography, 74, 174-191. 
Ramirez, T., Cortés, D., \& Garcia, A. 2001. Growth of North Alboran Sea sardine larvae estimated by otolith microstructure, nucleic acids and protein content. Journal of Fish Biology, 59, 403-415.

Raventós, N., \& MacPherson, E. 2001. Planktonic larval duration and settlement marks on the otoliths of Mediterranean littoral fishes. Marine Biology, 138, 1115-1120.

Reglero, P., Ciannelli, L., Alvarez-Berastegui, D., Balbín, R., López-Jurado, J.L., \& Alemany, F. 2012. Geographically and environmentally driven spawning distributions of tuna species in the western Mediterranean Sea. Marine Ecology Progress Series, 463, 273-284.

Rooker, J.R., Alvarado Bremer, J.R., Block, B.A., Dewar, H., De Metrio, G., Corriero, A., Kraus, R.T., Prince, E.D., Rodríguez-Marín, E., \& Secor, D.H. 2007. Life history and stock structure of Atlantic bluefin tuna (Thunnus thynnus). Reviews in Fisheries Science, 15(4), 265-310.

Sabatés, A., Zabala, M., \& García-Rubies, A. 2003. Larval fish communities in the Medes Islands Marine Reserve (north-west Mediterranean). Journal of Plankton Research, 25(9), 1035-1046.

Shanks, A.L. 2009. Pelagic larval duration and dispersal distance revisited. The Biological Bulletin, 216(3), 373-385.

Shanks, A.L., Grantham, B.A., \& Carr, M.H. 2003. Propagule dispersal distance and the size and spacing of marine reserves. Ecological Applications, 13(1), 159-169.

Smith, C.L. 1990. Moronidae. Pages 692-694 of: Quero, J.C., Hureau, J.C., Karrer, C., A., Post, \& Saldanha, L. (eds), Check-list of the fishes of the eastern tropical Atlantic, vol. 2. JNICT, Lisbon and SEI/UNESCO, Paris.

Smith-Vaniz, W.F. 1986. Carangidae. Pages 815-844 of: Whitehead, P.J.P., Bauchot, M.L., Hureau, J.C., Nielsen, J., \& Tortonese, E. (eds), Fishes of the north-eastern Atlantic and the Mediterranean, vol. 2. UNESCO, Paris.

Torres, A.P., Reglero, P., Balbin, R., Urtizberea, A., \& Alemany, F. 2011. Coexistence of larvae of tuna species and other fish in the surface mixed layer in the NW Mediterranean. Journal of Plankton Research, 33(12), $1793-1812$

Zulliger, D.E., Tanner, S., Ruch, M., \& Ribi, G. 2009. Genetic structure of the high dispersal AtlantoMediterreanean sea star Astropecten aranciacus revealed by mitochondrial DNA sequences and microsatellite loci. Marine Biology, 156, 597-610. 